NBER WORKING PAPER SERIES

ENERGY, OBSOLESCENCE, AND THE PRODUCTIVITY SLOWDOWN

Charles R. Hulten

James W. Robertson

Frank C. Wykoff

Working Paper No. 2404

NATIONAL BUREAU OF ECONOMIC RESEARCH

1050 Massachusetts Avenue

Cambridge, MA 02138

October 1987

We gratefully acknowledge the financial support by the Bureau of Labor Statistics, U.S. Department of Labor. The findings and opinions presented in this paper are strictly those of the authors and should not be attributed to BLS. We wish to thank Jerome Mark and William Waldorf of the Bureau of Labor Statistics, M. Wolfson of the Machinery Dealers National Association, Lloyd Sommers, and Victor Wykoff of Caterpillar Tractor Co. for their support and encouragement, and Ernst Berndt, Michael Harper, Dale Jorgenson, and Reza Ragozar for their comments and help. The research reported here is part of the NBER's research program in Productivity. Any opinions expressed are those of the authors and not those of the National Bureau of Economic Research. 
NBER Working Paper \#2404

October 1987

\section{Energy, Obsolescence, and the Productivity Slowdown}

\section{ABSTRACT}

The growth rate of output per worker in the U.S. declined sharply during the 1970's. A leading explanation of this phenomenon holds that the dramatic rise in energy prices during the $1970^{\prime}$ s caused a significant portion of the U.S. capital stock to become obsolete. This led to a decline in effective capital input which, in turn, caused a reduction in the reduction in the growth rate of output per worker.

This paper examines a key prediction of this hypothesis. If there is a significant link between energy and capital obsolescence, it should be revealed in the market price of used capital: if rising energy costs did in fact render older, energy-inefficient capital obsolete, prospective buyers should have reduced the price that they were willing to pay for that capital. An examination of the market for used capital before and after the energy price shocks should thus reveal the presence and magnitude of the obsolescence effect.

We have carried out this examination for four types of used machine tools and five types of construction equipment. We did not find a general reduction in the price of used equipment after the energy price shocks. Indeed, the price of used construction equipment - the more energy intensive of our two types of capital - tended to increase after 1973. We thus conclude that our data do not support the obsolescence explanation of the productivity of slowdown.

Charles R. Hulten

Chairman

Department of Economics

University of Maryland

College Park, MD 20742
James $W_{0}$ Robertson

Maxwell Stamp Associates

London

ENGLAND
Frank C. Wykoff

Department of Economics

Pomona College

Claremont, CA 91711 
Energy, Obsolesence, and the Productivity Slowdown

Output per worker in the U.S. business sector grew at an average annual rate of 3.08 from 1948 to 1973. From 1973 to 1984, however, this annual rate plunged to 1.18 . This is the widely publicized "productivity slowdown" that has attracted so much attention from economic researchers. ${ }^{1}$

Some analysts see the slowdown as a consequence of the changing structure of the U.S. economy - the increased importance of international trade, the shift in economic activity towards the service sector, and the changing demography of the labor force; others see the problem resulting from policy inflicted wounds such as increased tax burdens on income from capital and increased regulatory requirements; still others see the problem as due to macroeconomic trends in inflation and recession. Some even hold the view that the slowdown is an artifact of the data and really did not occur at all. ${ }^{2}$

A prime suspect, however, is the rapid and unexpected rise in energy prices imposed by the OPEC carte1 in 1973 and again in 1979. While there is still a debate over when the productivity slowdown started, few doubt that the sharpest decline occurred after 1973. The coincidence of this decline in most industrialized countries with the energy crisis is an obvious clue, and many analysts have suggested mechanisms through which higher energy prices cause economic growth to slow.

In this paper we examine one of the leading energy-related hypotheses. This hypothesis, advanced by Martin N. Baily (1981), holds that the rise in energy prices accelerated the rate of obsolescence of the U.S. stock of physical capital. Since conventional measures of the capital stock do not capture changes in the rate of obsolescence, conventional analyses of growth 
fail to identify this effect. Instead, they suppress it into a time trend or residual estimate of productivity change. Baily shows that this energy-induced obsolescence effect may have been large enough to account for most of the productivity slowdown.

If correct, the obsolescence hypothesis offers a sufficient explanation of the productivity slowdown. Baily's evidence is, however, based on the correlation between the rise in energy prices and the decline in Tobin's average $q$, and is subject to the criticism that the $q$ ratio could have fallen during the 1970's for reasons unrelated to the energy crisis (e.g. the rise in effective income tax rates). ${ }^{3}$ A more direct test is needed to establish the extent to which the energy price increases induced obsolescence in the stock of capital.

The model of this paper provides such a test. If there is a significant link between energy and obsolescence, it should be revealed in the price of old capital: if rising energy costs did in fact render older, energy-inefficient capital obsolete, prospective buyers should have reduced the price that they were willing to pay for that capital (a decline in asset value is, indeed, the definition of obsolescence). ${ }^{4}$ An examination of the market price of used capital before and after the energy price shocks should thus reveal the sign and the magnitude of the Baily effect.

We have carried out this examination for four types of used machine tools and five types of construction equipment. Our principal conclusion is that data for these assets do not support the obsolescence hypothesis. There is no systematic downward shift in used asset prices after 1973, and, for construction equipment, the shifts tend to be upward, not downward. 5

The paper is organized as follows: In sections II and III we review the 
recent literature on the role of energy in the productivity slowdown. In the subsequent two sections we set out our model of used asset prices and relate it to the obsolescence hypothesis. We then describe our data and present the empirical findings in sections VI and VII.

\section{Energy and Economic Growth}

Energy can be directly related to economic growth via a production function in which gross output, Q, is assumed to depend on the quantities of capital, $\mathrm{K}$, 1abor, $\mathrm{L}$, energy, $\mathrm{E}$, and material inputs, $M:^{6}$

$$
Q=A F(K, L, E, M) \text {. }
$$

In the production function (1), all variables are implicit functions of time and the variable $A$ is included separately to allow for Hicks-neutral shifts in the function over time, i.e., to allow for changes in $Q$ not captured by changes in the input quantities. The term $A$ is thus a surrogate for technical change, but also includes the effects of such factors as managerial efficiency and worker effort.

The fundamental equation of growth analysis can be derived from the production function under the assumption that each input is paid the value of its marginal product. Logarithmic differentiation of F yields: ${ }^{7}$

$$
\hat{Q}=S_{K} \hat{K}+S_{L} \hat{L}+S_{E} \hat{E}+S_{M} \hat{M}+\hat{A}
$$

Hats over variables indicate rates of growth, and S's represent the shares of total cost allocated in each input; $S_{L^{\prime}}$ for example, represents labor's share 
of total costs; the variable $\hat{A}$ represents the rate at which the technology shifts over time (and is called the rate of change of total factor productivity). All variables in (2) except $\hat{A}$ can be measured directly or imputed, so $\hat{A}$ can be measured as a residual.

If one assumes constant returns to scale, then the cost shares sum to one and (2) can be written as

$$
\hat{Q}-\hat{L}=S_{K}(\hat{K}-\hat{L})+S_{E}(\hat{E}-\hat{L})+S_{E}(\hat{M}-\hat{L})+\hat{A}
$$

The left hand side of equation (3) is the growth rate of output per labor-hour - "labor productivity." Equation (3) states that labor productivity equals the sum of the growth rate of the capital-labor ratio, weighted by capital's share of total cost, the growth rates of energy and materials per labor-hour, weighted by their cost shares, and the growth rate of total factor productivity.

Equation (3) provides a framework for analyzing the slowdown in labor productivity. Any change in $\hat{Q}-\hat{L}$ after 1973 must be associated with changes in the variables on the right hand side of (3). In particular, the impact of the energy costs on $\mathrm{Q} / \mathrm{L}$ can be linked directly to changes in the energy intensity of production, E/L. This link suggests the following explanation for the productivity slowdown: the rise in the price of energy relative to other input prices caused the demand for energy to fall and this reduced the growth rate of $\hat{E}-\hat{L}$, which caused $\hat{Q}-\hat{L}$ to slow.

This explanation for the slowdown was among the first considered. ${ }^{8}$ However, the problem with this explanation is that energy's cost share ( $S_{E}$ ) is very small, about 28 for U.S. manufacturing, so that even large changes in $\hat{E}-\hat{L}$ 
will have a small impact on $\hat{Q}-\hat{L}$. An even more important problem is that, for U.S. manufacturing industries, the decline in E after 1973 was largely offset by a concomitant decline in L. Thus, according to data from the Bureau of Labor statistics, covering the period 1948-1981, almost no change in $\hat{E}-\hat{L}$ occurred after 1973. This data - shown in Table 1 - leads to the conclusion, expressed in a similar study by Berndt (1980), that "energy price or quantity variations since 1973 do not appear to have played a significant direct or indirect role in the slowdown of labor productivity in U.S. manufacturing" . $(\mathrm{p} .72)$.

Another possible link between energy and economic growth was advanced by Hudson and Jorgenson (1978) and Berndt and Wood (1979). If energy and capital are complements in production, an increase in the price of energy should reduce the demand for capital and trigger a substitution of other inputs for capital. The impact of higher energy costs would then appear as a reduction in the growth rate $\mathrm{K} / \mathrm{L}$, as well as in the $\mathrm{E} / \mathrm{L}$ term of (3). Unfortunately, the data of Table 1 do not support this hypothesis either: the decline in $\mathrm{E} / \mathrm{L}$ is small and explains only $5 \%$ of the decline in the growth of $Q / L$, while the growth rate of the traditionally measured capital-1abor ratio actually increased after 1973 .

According to the estimates of Table 1, the slowdown in labor productivity is entirely related to a decline in the growth rate of total factor productivity. This would appear to exonerate the energy crisis as the primary cause of the productivity slowdown, and to shift attention to the residual variable A that some call "a measure of our ignorance." This conclusion, however, presumes that the price of energy and the growth rate of total factor productivity are not linked. In fact, two such links have been established. 
Table 1.

The Productivity Slowdown in U.S. Manufacturing

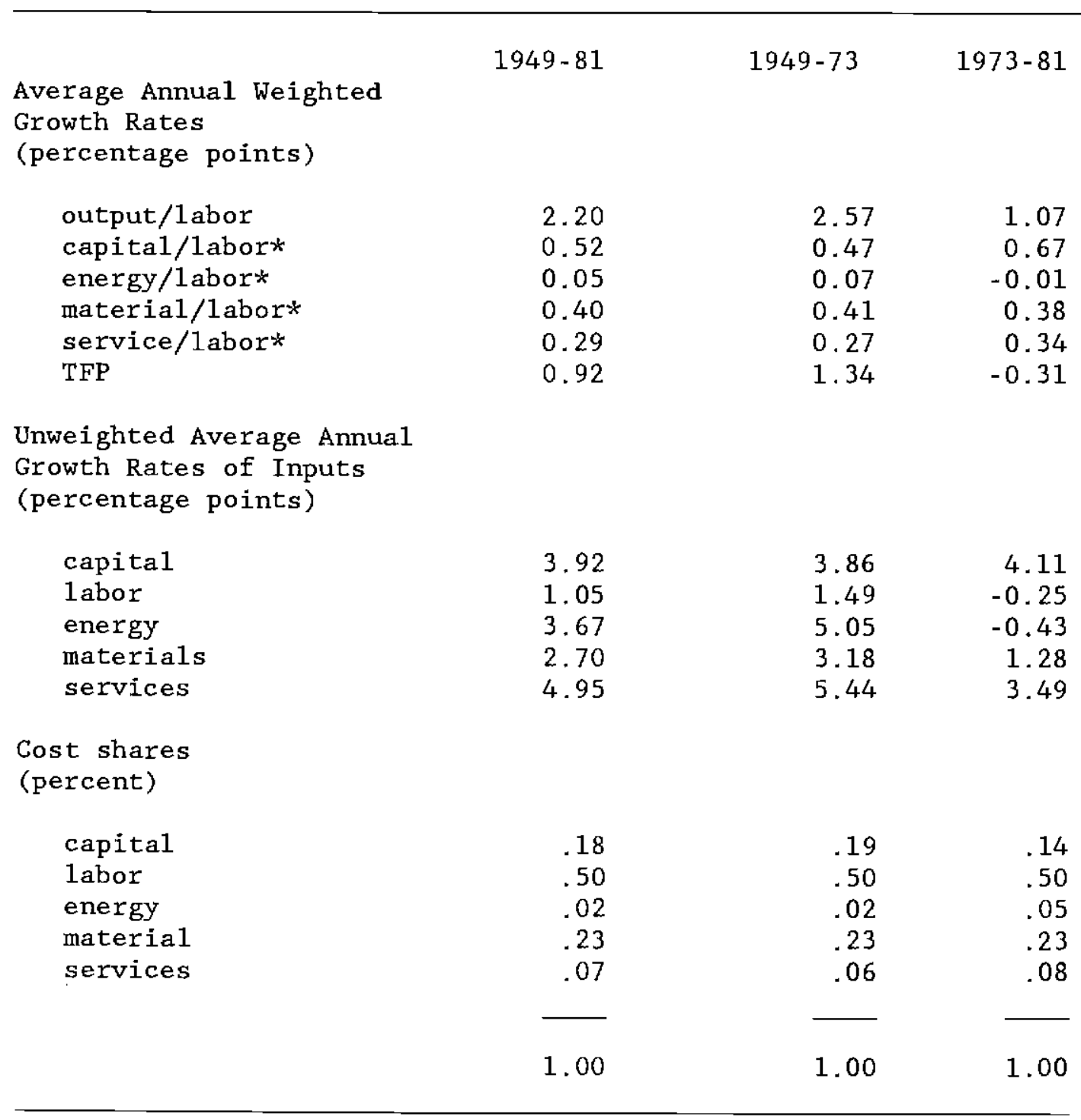

*weighted by cost shares

Source: Bureau of Labor Statistics (1985)

First, Jorgenson and Fraumeni (1981) and Jorgenson (1984) have argued that total factor productivity depends on the price of energy through a bias in 
technical change. Their argument can be illustrated with a model in which technical change occurs by augmenting particular factors of production. In our framework, this may be expressed with the following production function:

(4) $Q=F\left(A_{K} K, A_{L} L, A_{E} E, A_{M} M\right)$,

where $A_{i}$ is the factor augmentation parameter for the $i$ th type of input; total factor productivity change is then given by:

$$
\hat{A}=S_{K} \hat{A}_{K}+S_{L} \hat{A}_{L}+S_{E} \hat{A}_{E}+S_{M} \hat{A}_{M} \text {. }
$$

The average rate of productivity change is thus the share-weighted average of the rates of factor augmentation.

Jorgenson and Fraumeni show that a change in the price of energy can change the average rate $\hat{A}$, even though the individual $\hat{A}_{i}$ are not affected. This occurs when the price of energy rises and when the relative bias with respect to energy, $\hat{A}_{E}-\hat{A}$, is positive, i.e., technical change is energy-using. The average rate falls, in this case, because the energy price increase causes production to become less energy intensive (other things equal). This means that technical progress augments that input whose quantity is falling relative to other inputs.

Jorgenson and Fraumeni find that the bias in technical change was energy augmenting in a majority of U.S. industries, and thus have a potential explanation for the productivity slowdown. However, they do not offer an overall quantitative appraisal of the extent to which their energy price effect contributed to the productivity slowdown. 
III. The Baily Hypothesis

The second link between energy costs and total factor productivity was developed by Martin N. Baily (1981). Baily noted that conventional measures of capital stock do not allow for changes in the rates of utilization or variations in the rates of depreciation of capital. Instead, the capital stocks are typically measured using a perpetual inventory method - that is, by cumulating investment during year $t$ and subtracting the depreciation and retirement of the existing stock. Depreciation and retirement are assumed to be stationary processes which do not change with economic events.

According to Baily, this method of estimating capital is inadequate for measuring the contribution of capital to the growth of output, since the sharp rise in energy costs may have caused firms to utilize their old energy-inefficient capital less intensively and to retire it earlier. A trucking company, for example, may have had the incentive to operate its relatively energy-efficient trucks more frequently, and reserve its less efficient vehicles for peak load capacity. In this case, the rise in energy costs causes the trucking firm to some use of its capital less intensively. Yet, perpetual inventory measures of capital, by their very nature, cannot capture this effect.

An important conclusion follows from this line of analysis: If utilization effects are present, they will be suppressed into the residual estimate of total factor productivity and thus misstate the impact of energy prices on capital. To illustrate this mismeasurement problem formally, let $\mathrm{K}^{*}$ denote the true growth rate of capital input (i.e. the rate adjusted for utilization) and $A^{*}$ the true rate of total productivity growth; equation (3) 
then becomes

$$
\hat{Q}-\hat{L}=S_{K}\left(\hat{K}^{*}-\hat{L}\right)+S_{E}(\hat{E}-\hat{L})+S_{M}(\hat{M}-\hat{L})+\hat{A}^{*}
$$

Comparing (3) and (6), we find that

(7) $\hat{A}=\hat{A}^{*}+S_{K}\left(\hat{K}^{*}-\hat{K}\right)$.

If $\hat{\mathrm{K}}$ overstates $\hat{\mathrm{K}}^{*}$ because utilization is ignored, then $\hat{\mathrm{A}}$ will be biased downward by an amount equal to the change in utilization $\left(\hat{K}^{*}-\hat{K}\right) \operatorname{multiplied}$ by capital's share in total cost. It follows immediately that the sharp decline in the conventionally measured growth rate of total factor productivity after 1973, evident in the estimates of Table 1 (which are based on perpetual inventory calculations of $\hat{\mathrm{K}}$ ), may have been caused instead by an energy-induced decline in the rate of utilization of old capital. ${ }^{9}$

Any test of the Baily hypothesis must deal with the difficult problem of measuring the unobserved variable $\mathrm{K}^{*}$. Baily provides an ingenious solution to this problem: he assumes a "putty-putty" Cobb-Douglas technology in which input substitution can occur both ex post and ex ante; he then derives a production function in which output depends on the value of the capital stock rather than on the quantity of capital. In our framework, this implies that the production function has the form:

$$
Q=F\left(K^{*}, L, E, M, A^{*}\right)=F\left(V K, L, E, M, A^{*}\right),
$$

with the value of the stock (VK) substituted for the quantity of capital $\mathrm{K}^{*}$. 
In this model, variations in the value of the capital stock act as a surrogate for variations in the utilization of this stock, given $\mathrm{K}$.

The VK in (8) nominally refers to the present value of the income associated with the stock of capital. VK is therefore equal to the amount that rational investors would be willing to pay for the capital, and should thus be equal to the financial value of the firm (less "goodwill"). A financial measure of VK could thus be used as a surrogate for $K^{*}$. Baily, however, uses a slightly different approach based on Tobin's $q$ theory of investment decision. Tobin's average $q$ as is defined as

(9) $\quad \mathrm{q}=\mathrm{VK} / \mathrm{P}_{\mathrm{I}} \mathrm{K}$,

(where $P_{I}$ is the price of a new unit of capital stock, and $P_{I} K$ is the replacement cost of the capital stock). In view of (9) we can write VK as ${ }^{\mathrm{qP}}{ }_{\mathrm{I}} \mathrm{K}$ and substitute the result into the production function. Since $\mathrm{K}$ is measured in physical units and $P_{I}$ is the price of new investment goods, an obsolescence induced decline in VK is reflected in q.

According to Summers (1981), Tobin's $q$ fell during the 1970's (from 1.029 in 1973 to 0.747 in 1977), and Baily concludes that the movement in $q$ is more than sufficient to explain the productivity slowdown. The obsolescence hypothesis thus provides a complete explanation of the productivity puzzle.

There are, however, at least two difficulties with this explanation. First, the decline in Tobin's q could be due to any number of factors, not just energy price shocks. Sumners, for example, writing in the same volume as Baily, attributes the decline in $q$ to perverse tax policy. Indeed, Baily himself is careful to note that the decline in effective capital stock may 
have been caused by structural changes in the U.S. economy due to such factors as increased foreign trade. The use of Tobin's $q$ to explain the total factor productivity residual may simply substitute one "measure of ignorance" for another.

The second problem with using $q$ theory arises because changes in the value of the capital stock due to obsolescence do not necessarily imply changes in the effectiveness of capital used in production. In Solow's vintage model, for example, the introduction of superior new capital reduces the net income accruing to old capital, but this capital continues to be operated so long as the net income of the vintage is positive. And, as we sha11 see below, it is even possible that older capital is operated more intensively for a period of time after the energy price shock renders old capital obsolete. This can occur if there is substantial uncertainty about the nature and speed of introduction of new energy saving technology.

The studies by Berndt and Wood (1984) and Berndt, Mori, Sawa, and Wood (1985) provide a more direct approach which avoids asset valuation problems associated with Tobin's q. They develop a putty-clay mode1 in which each vintage of capital is built with a particular energy intensity based on the relative energy-capital prices prevailing at the date the capital was placed in service. Each vintage can be operated at a different intensity by switching labor from one vintage to another. Since energy and capital are "bundled," a rise in the cost of energy will cause those vintages designed under the assumption of lower energy prices to be operated less intensively.

In this framework, utilization is defined as $B_{t}=K_{t}^{*} / K_{t}$, where $K_{t}^{*}$ again denotes effective capital input and $k_{t}$ the stock of capital. It is then shown that 


$$
\frac{\partial \ln B_{t}}{\partial \ln P_{E K, t}^{*}}=-\sigma
$$

where $\mathrm{P}_{E K, t}^{*}$ is the expected relative price of capital services and energy and $\sigma$ is the ex ante elasticity of substitution between capital and energy. From (7), it is evident that changes in $B_{t}$ introduce biases in the measurement of total factor productivity. Indeed, (7) can be rewritten as

$$
\text { (7') } \quad \hat{A}=\hat{A}^{*}+S_{K} \hat{B}_{t} \text {. }
$$

This expression, in conjunction with (10), ties the mismeasurement of total factor productivity growth directly to changes in the expected price of energy .

Berndt and Wood (1985) report an average reduction in $B_{t}$ of 298 between 1973 and 1974, and a net change of $5 \%$ between 1973 and 1978. The second energy price shock reduced $B_{t}$ by $7 \%$ between 1979 and 1980 , and by $3 \%$ between 1979 and 1981. This pattern suggests that the Berndt-Wood correction is primarily cyclical and that the secular change in $B_{t}$ over the 1970's was much more modest. Indeed, the average annual growth rate of $B_{t}$, i.e. $\hat{B}_{t}$, was $2.1 \%$ over the period 1973-81. Since capital's share of income was .14 for this period (according to Table 1), (7') implies a correction of $0.3 \%$ per year in $\hat{A}$. Since measured total factor productivity grew at an average annual rate of 1.348 over the period $1949-73$, and then declined to $-0.31 \%$ over the period 1973-81, the Berndt-Wood correction is not large enough to explain the decline in $\hat{A}$ as measured error. 10

This finding is repeated in Berndt et al. (1985), who relate (10) to the 
sources of growth model (2), using a somewhat different rationale for (10). They find that, even when large values of $\sigma$ are assumed, the implied utilization correction explains almost none of the productivity slowdown in U.S. manufacturing. In sum, the results of Berndt et al. do not appear to support the hypothesis that the energy crises was the primary cause of the productivity slowdown.

\section{The Vintage Price Approach}

We adopt in this study a variant of Baily's willingness-to-pay approach that avoids Tobin's q theory. Instead of inferring the value of capital stock (VK) from financial data which values the entire firm, we estimate capital value directly from market data on used equipment prices. This is possible because, at any time $t$, the aggregate value of the capital stock is the sum of the values of the separate vintages:

$$
\mathrm{VK}=\sum_{\mathrm{s}=0}^{\mathrm{T}_{\max }} \mathrm{P}_{\mathrm{I}, \mathrm{s}} \mathrm{K}_{\mathrm{s}}
$$

This equation indicates that, in principle, VK could be measured by valuing the separate components of physical capital assets. 11

We assume that the $P_{I, s}$ in (11) are equal to the amount an investor would be willing to pay for a piece of capital. This, in turn, is assumed to be equal to the present value of the expected net income stream generated by the asset. For an s-year old asset, this present value is given by: 


$$
P_{I, s}=\sum_{t=0}^{T_{s}} \frac{P_{K, s+t}}{(1+r)^{t+1}}
$$

where $\mathrm{T}_{s}$ is the optimal retirement age of an s-year old asset, $r$ is the constant expected discount rate, and $\mathrm{P}_{\mathrm{K}, \mathrm{s}+\mathrm{t}}$ is the expected net income flow accruing to the asset of age s+t years in the future. Under constant returns to scale,

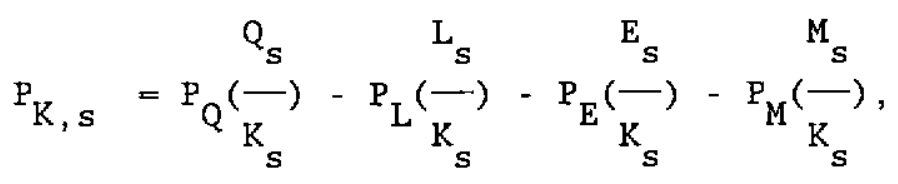

since the value of the output produced by a unit of capital just equals the cost of all the inputs. In a putty-clay model, the quantity ratios are fixed and a rise in $P_{E}$, ceteris paribus, will cause $P_{K, s}$ to fall. The lower net yield to energy-using capital is reflected in $\mathrm{P}_{\mathrm{K}, \mathrm{s}}$ and is "capitalized" in price of used capital via (12). Furthermore, the percentage decline in price will tend to increase with age and the optimal time to retirement will be shortened. These capitalization effects occur without variation in utilization. They will be reinforced if assets of vintage-s are utilized less intensively, as Baily and Berndt et al. postulate.

The geometric interpretation of this model is given in Figure 1 . The curve $A A$ is the locus of prices $P_{I, s}$ plotted against age, $s$, for a given year t. The curve AA is depicted with a negative slope, reflecting the fact that the value $P_{I, s}$ falls with increasing age because: (1) the date of retirement 
is drawing closer (i.e. because $T_{s}$ is smaller); and (2) older assets may generate less income because of increased maintenance expenses or decreased productivity (i.e. because $\mathrm{P}_{\mathrm{K}, \mathrm{s}}$ is smaller). While we have drawn this "age-price" profile as convex, following the findings of Hulten and Wykoff (1981a, 1981b), the profile could, in principle, be linear, concave, or irregular.

The capitalization effects discussed above are illustrated in Figure 1 by a downward shift in the age-price profile from $A A$ to $A^{\prime} A^{\prime}$. As $P_{K, s}$ falls because of an increase in $\mathrm{P}_{E}$, and possibly because utilization decreases, $\mathrm{P}_{I, s}$ falls for each age $s$. A new age-price is thus established at $A^{\prime} A^{\prime}$ immediately after the energy price shock. In subsequent years, the introduction of new energy-efficient assets may cause a portion of $A^{\prime} A^{\prime}$ to shift upward, in which case the age-price profile has a discontinuity at the age, $\mathbf{s}$, corresponding to the time of the energy price shock.

This simple geometric framework suggests the following measurement procedure: Assume that the age-price profiles of a given set of assets are similar and collect data on the resale value of assets of different vintages; then, fit separate curves for the years before and after the energy crisis. The impact of the energy crisis should then be revealed by the magnitude of the downward shift in the post-energy shock age-price profiles.

The appearance of a downward shift in the age-price profile must, however, be interpreted with care. The shift may be the result of factors not related to energy prices. Similarly, the failure to detect a shift may be due to other factors offsetting the energy effect. However, if this is the case, the impact of the energy price shock is neutralized and the energy crises is not a plausible explanation of the productivity slowdown. 
Second, a shift might signal the capitalization of higher energy costs without any change in output, as $P_{I, s}$ falls because $P_{E}$ has risen, but $F(K, L, E, M$,$) remains constant. In this case, there is no mismeasurement of$ capital and no explanation of the productivity slowdown. Thus, a downward shift in the age-profile does not necessarily imply confirmation of Baily's obsolescence hypothesis.

On the other hand, it is hard to imagine a significant decline in the rate of utilization of an asset, or a significant increase in the rate of retirement, that does not lead to a reduction in the asset's inflation-corrected value. If firms plan to use a given vintage of capital less intensively after an energy price shock, it is unlikely that the market would be willing to pay more for capital of that vintage after the price shock than before. A failure to detect a downward shift in the age-price profile thus constitutes evidence against the importance of the energy-induced obsolescence effect and the lower utilization of capital effect. It would also imply that the model of equations (11) - (13) is of limited relevance, since it means that an increase in $\mathrm{P}_{E}$ does not lead to a decline in $\mathrm{P}_{\mathrm{I}, \mathrm{s}}$.

\section{The Econometric Model}

The framework implied by Figure 1 requires further development in order to serve as an econometric model. First, and most important, inflation must be taken into account. Then, a functional form that is highly flexible for estimating the age-price profile must be developed so that apparent shifts in the function are not the result of functional form misspecification.

General inflation and market-specific factors will cause the asset value 
of all vintages to change over time. This causes the age-price profile to shift over time, from $A A$ to $B B$ to $C C$ in Figure 2. As an asset ages, the change in its price is the sum of two effects: a movement along the age-price profile from a to $c$ (aging and obsolescence) and a movement from $c$ on one profile to a point $b$ on the next (revaluation). The observed path of the asset's price with respect to time is the curve PP.

Accurate measurement of the revaluation effect is crucial for the analysis, because an overcorrection for inflation will result in an excessive shift in the profile. Suppose, for example, the actual inflation rate causes a 108 vertical shift in the profile $A A$, to $B B$ in Figure 2. An accurate correction for inflation would be conceptually equivalent to shifting the curve $\mathrm{BB}$ downward until it is colinear with $\mathrm{AA}$. An inaccurate correction, on the other hand, will create the appearance of a shift in the inflation-corrected $B B$ relative to $A A$, even though none has occurred. Suppose, for example, that inflation is erroneously thought to be 158 when it is really 108. The inflation correction to $B B$ will cause the new curve to be below AA, giving the appearance that some event has caused the real age-price profile to shift downward.

Revaluation can be dealt with in two ways - by use of an existing index or by direct estimation. If revaluation is mainly caused by a general inflation, the deflation of used asset prices by a general price index is an appropriate device for capturing the shift of the profiles. If revaluation has more asset specific causes, however, then deflation by an asset specific price index for new equipment may be necessary. This course of action is, however, potentially dangerous. If new assets do not embody energy saving technology, the energy price shock may also affect the price of new assets. 
If this is the case, deflation of used asset price by an index of new asset prices will tend to eliminate the downward shift in the age-price profile, which has actually occurred.

One way out of this bind is to assume that the supply of new capital is highly elastic. In this case, a change in energy prices will not greatly affect the equilibrium price of new assets. On the other hand, the supply of used assets is inelastic so that capitalization via (12) can take place. Deflation of used asset prices using new asset prices is then appropriate. In addition to deflation, the inclusion of a time trend in the econometric model may also be useful, because no single index will capture all intertemporal shocks to asset values. Furthermore, since the rate of revaluation cannot be assumed to follow a smooth trend (witness the history of the general rate of inflation in the 1970's), the functional form selected for the regression analysis must be highly flexible. Our general procedure for estimating revaluation has been to assume a flexible functional form in time trend and perform all tests both on undeflated prices and on prices deflated by a machinery and equipment price index.

The functional form must be flexible for other reasons as well. The basic objective of the analysis is to approximate the age-price profiles of Figure 2 and to detect any shifts occurring after 1973 not associated with revaluation. In so doing, one cannot assume, a priori, that the shapes of the age-price profiles themselves are convex, as shown in Figures 1 and 2. There is considerable controversy over this point, as noted in Hulten and Wykoff (1981a, 1981b), and while the balance of the evidence favors the convex form, the shape of the age-price profile is an empirical issue that should be resolved by data analysis, not by assumption of a restrictive form. 
The functional form should therefore be able to discriminate among a wide range of possible age-price profiles: "one-hoss shay" (concave), straight-line (linear), geometric (convex) depreciation, and others as well. Even apart from inflation effects, failure to allow for sufficient flexibility can result in false shifts in the estimated age-price profiles. This can occur because of cohort effects in the underlying data: If assets are constructed in "binges," the sample data will not be distributed uniformly over the age-price profile. If the underlying age-price profiles are convex, but linear functions are used in the regression analysis, then the profiles may appear to shift downward after 1973 when, in fact, no shift has occurred. These considerations led us to adopt the Box-Cox power transformation model used in the earlier depreciation studies of Hulten and Wykoff. ${ }^{12}$ The Box-Cox model has the following form:

$$
\frac{\mathrm{P}_{i}^{\theta_{0}}-1}{\theta_{0}}=\alpha+\beta \frac{\mathrm{S}_{i}^{\theta_{1}}-1}{\theta_{1}}+\gamma \frac{\mathrm{T}_{i}^{\theta_{2}}-1}{\theta_{2}}+\epsilon_{i}
$$

where $P_{i}$ is the observed price of the used asset (corresponding to $P_{I, s}$ in equation (11)), $S_{i}$ is the age of the asset at the time of sale, $T_{i}$ is the year that the transaction took place, and $\epsilon_{i}$ is a random disturbance term. The coefficients $\alpha, \beta$, and $\gamma$ are conventional slope and intercept parameters; $\theta_{0}, \theta_{1}$, and $\theta_{2}$ are power transformation parameters that fix the form of the function. When $\theta=(1,1,1)$, the form is linear; when $\theta=(1,0,0)$, it is geometric, and $\theta=(0,0,0)$ yields the $\log -\log$ firm.

This model was estimated under the assumption that $\epsilon_{i}$ is independently normally distributed. Since (14) is highly nonlinear, maximum likelihood 
methods, combined with grid searches, were used to estimate the various parameters. The analysis was carried out with real (i.e., inflationcorrected) $P_{i}$ and with nominal (i.e., uncorrected) $P_{i}$.

The mode1 (14) does not by itself provide a direct estimate of any shift in the age-price profile. To remedy this, we adjust (14) to include a dumm variable d equal to zero before 1973 and one thereafter:

$$
\begin{aligned}
& \frac{{ }_{P_{i}{ }^{\theta}}-1}{\theta_{0}}=\alpha+\beta \frac{{ }_{\mathrm{S}_{i}}^{\theta_{1}}-1}{\theta_{1}}+\gamma \frac{{ }_{\mathrm{T}_{\mathrm{i}}{ }^{2}-1}}{\theta_{2}} \\
& +\phi \mathrm{d} \frac{\mathrm{s}_{i}^{\theta_{1}}-1}{\theta_{1}}+\psi \mathrm{d}+\epsilon_{\mathrm{i}}
\end{aligned}
$$

The theory of the preceding section suggest that $\phi$ and $\psi$ should be negative if the age-price profile shifted downward after 1973.

\section{The Data}

These econometric models were fitted using data on two general classes of assets; heavy duty construction equipment, which includes five assets: D9-tractors, D6-tractors, motor graders, rubber tire loaders, and backhoes; and machine tools, which covers four general types of assets: turret lathes, milling machines, presses, and grinders. These assets were selected partly because of availability of data sources and partly because they represent one 
group of energy-intensive assets (construction equipment) and one group of non-energy-intensive assets widely used in the manufacturing industry. Direct energy cost increases should reduce the net return to the former more than the latter, but energy cost increases may indirectly lower the capital values of the latter, to the extent that higher energy costs reduced demand for energy-using products made by machine tools and thereby lowered quasi rents.

The construction equipment data come from annual issues of International Equipment Exchange and cover the years 1968 to 1982 . Each observation corresponds to a single transaction and contains information covering the auction price and individual asset characteristics such as: serial number, age, condition, ancillary equipment (tractor blade, canopy, air conditioners), and model number. In some instances, the prices may not reflect actual transactions but rather sub rosa agreements in which the owner agrees to buy back his asset if the auction price does not exceed his reservation price. However, the extent of this "buy-back" activity is impossible to document, and we have no way of knowing which transactions represent buy-backs.

The machine tool data were collected from auction reports compiled by the Machine Dealers National Association (MDNA). These reports cover the period between 1954 and 1983 and, for the most part, were issued monthly. ${ }^{13}$ Each observation typically includes the auction price, the general condition of the asset, the serial number, and the configuration of that particular asset (i.e., whether it includes special equipment, the size of the chuck, etc.). If the age of the asset was not noted in the auction report, we were able to determine the age of the asset from the serial number. 14 
The available data for the construction equipment was sufficiently detailed to permit us to adjust prices to reflect differences in asset configuration. In other words, the adjusted prices for these assets reflect only the basic asset and not different asset add-ons, (e.g. the type of engine, blade attachments, general conditions, etc.).

While some of the data for machine tools contains information on asset configuration, the coverage is too sparse to permit the estimation of the effects of different asset options on prices. In order to achieve sufficient sample sizes, the minimum requirements for inclusion were that each observation have the price, and either the age or a serial number which would permit us to determine the age.

In the case of machine tools, we attempted to limit the variance in prices due to differences in makes and models by restricting the sample and through the use of dummy variables. For turret lathes, we restricted the sample to lathes manufactured by Warner and Swasey, one of the largest producers. Dummy variables were used to distinguish between different models. The milling machine sample was restricted to machines manufactured by Bridgeport, one of the most widely used machine tool brands in the world. The press sample consisted mainly of machines manufactured by Bliss Mfg. Co. and a few others. Obtaining a sample of sufficient size was more difficult for grinders, therefore observations for grinders produced by five different manufacturers were used, but the sample was dominated by machines produced by two firms.

Despite potential shortcomings, we assembled substantial samples of used asset auction prices. A summary of the sample characteristics is presented in Table 2. Sample sizes range between 370 observations for back hoes to 1241 
Table 2.

Summary Statistics of Project Date

\begin{tabular}{lcccccc}
\hline Asset Class & $\begin{array}{l}\text { Number } \\
\text { of Obs }\end{array}$ & $\begin{array}{c}\text { Max } \\
\text { Age }\end{array}$ & $\begin{array}{c}\text { Sample } \\
\text { Years }\end{array}$ & Age & Year & Price \\
\hline Construction Equipment: & 1241 & 27 & $1968-82$ & 10 & 1976 & 31235 \\
D9 Tractor & 1063 & 38 & $1968-82$ & 11 & 1976 & 19454 \\
D6 Tractor & 1050 & 38 & $1968-82$ & 14 & 1975 & 18691 \\
Motor Grader & 554 & 19 & $1968-82$ & 8 & 1979 & 40776 \\
Rubber Tire Loader & 370 & 19 & $1968-82$ & 7 & 1978 & 6832 \\
Back Hoe & & & & & & \\
Machine Tools: & 963 & 64 & $1954-83$ & 26 & 1965 & 4611 \\
Turret Lathes & 1027 & 42 & $1954-83$ & 12 & 1971 & 2232 \\
Milling Machines & 783 & 59 & $1954-83$ & 20 & 1970 & 4765 \\
Grinders & 430 & 60 & $1954-83$ & 23 & 1967 & 7059 \\
Presses & & & & & &
\end{tabular}

observations for D9 tractors. Several general characteristics of the two major asset classes emerge from these data. Construction equipment assets are typically more expensive and shorter lived than machine tools. The rather high average ages for machine tools, greater than 20 years old for three classes are noteworthy.

Average prices by age interval are shown in Figure 3 for all nine assets. Prices were first adjusted for inflation using the Bureau of Labor Statistics deflators for metal cutting machine tools and for construction equipment. Average prices were then calculated by age for the pre- and post-energy crisis 
eras. The resulting curves are actual age-price profiles corresponding to the age-price profiles depicted in Figures 1 and 2. Inspection of Figure 3 reveals the characteristic downward form of the age-price profile. Assets tend to lose value as they age, and, tend to lose relatively more value in the earlier years of life. This is consistent with most other studies of used asset prices.

Figure 3 also sheds some light on the capitalization of higher energy costs into capital values issue, at least for construction equipment. The age-price profiles of these assets appear to shift upward in three cases and might shift upward in one other case. The picture for machine tools is much less clear. Given the much greater variance in the machine tool prices within each class, this lack of clarity is not surprising. Recall that the machine tool data were not standardized for different add-ons, as were the construction equipment data. Thus, the post-1973 age-price profiles overlap the pre-1973 profiles leaving some ambiguity regarding the price decline issue. These ambiguities will be addressed in the formal econometric analysis of the following section.

\section{Econometric Results}

The parameters of (15) were estimated using maximum likelihood techniques, with deflated asset prices used as the dependent variable. The results are presented in Table 3 . The estimated coefficients of the age variable are uniformly negative, as expected, and statistically significant at conventional levels. The coefficients of time are significant in less than half the nine cases and the signs of the significant coefficients are evenly 


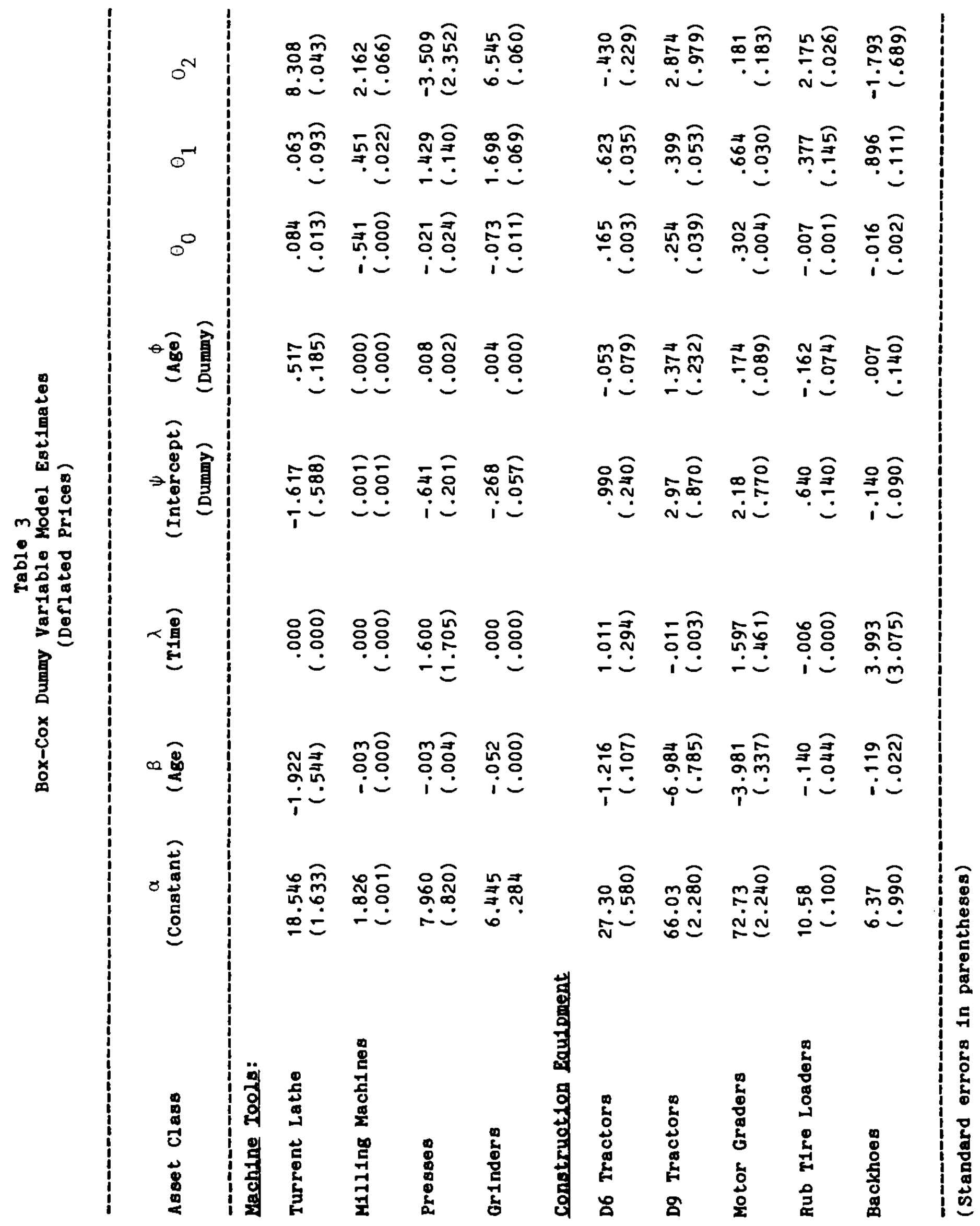


divided between positive and negative. Since the time variable is introduced in addition to the deflation procedure as a correction for inflation, this last result suggests that the deflation procedure did not systematically overor under-estimate inflation.

The estimated coefficients of the intercept dummy variable, $\psi$, were significant and positive for four of the five construction equipment classes. This indicates, other things equal, an upward shift in the age-price profile. The fifth class, back hoes, yielded a negative, but statistically insignificant, estimate. The machine tool classes on the other hand, yielded significantly negative estimates of the intercept dumny variable in three of the four asset classes. The fourth class, milling machines, yielded a statistically insignificant but positive estimate.

Estimates of the intercept dummy variable are not sufficient to determine the overall shift in the age-price profile. The slope dumny variable, $\phi$, indicates the degree to which the slope of the profile "twists" over time. The post-energy crisis age-price profile can thus intersect the pre-crisis profile and the overall result can therefore be ambiguous. To check this possibility visually, we have plotted the pre- and post-1973 profile in Figure 4. These plots confirm that crossing does occur in the milling machine and rubber tire loader classes. The remaining construction equipment classes show an upward shift in the age-price profile and the remaining machine tool classes show a downward shift.

Maximum likelihood estimates of the parameters in (15) were also obtained using the undeflated used assets prices. These results are reported in Appendix Table 1. The results were much the same as in the deflated case, except that the coefficient of time tends to be statistically significant in 
more cases and the sign is uniformly positive, as might be expected. The estimates of the intercept dummy variable are now uniformly significant, but the dichotomy between the two general classes is still evident.

These results suggest that the post-1973 shift in the age-price profile is highly asset specific. This pattern does not lend support to the obsolescence hypothesis since the more energy-intensive class of assets, construction equipment, apparently become more valuable after the energy crisis, not less valuable as predicted by the obsolescence hypothesis. ${ }^{16}$

If there is any pattern evident in Figure 4, it is consistent with the hypothesis that energy costs were not a significant factor in used asset valuation. In this case, one would predict upward or downward shifts according to market-specific forces not related to energy. A study of two general types of assets might then yield a random distribution of shifts, possibly like those observed in Figure 4. Further research with additional asset categories would be useful in sorting out the competing hypotheses. 17 Another possible explanation for the upward shifts is that the model of Section III fails to capture the full complexity of the problem. It may be that the price shock created uncertainty about the appropriate technology and about relative prices in the new post energy-price shock period. An implication of the Solow vintage capital model is that, under uncertainty, expected changes in future technology are relevant for deciding whether to adopt the most recent innovation. ${ }^{18}$ This uncertainty might therefore have led to a wait-and-see strategy in which new capital investment was deferred. If this occurred, then older assets would have been used more intensively than before and would be relatively more valuable. It is not clear, however, why this effect should apply to one type of asset but not 
another. 19

In conclusion, it should be stressed that since our model does not allow for the influence of other factors, we cannot completely rule out energy price effects. The energy shocks of the $1970^{\prime}$ 's may have had a partial effect which was offset by other factors. However, even if this were the case, it is not appropriate to conclude that the energy shock caused the productivity slowdown.

\section{Summary}

The recent collapse in energy prices gives renewed significance to the link between energy costs and industrial economic growth. If the 1970's energy price increase shocks retarded growth, then the subsequent fall in the mid 1980's may harbinger more rapid future growth. Unfortunately, this link has been hard to establish, and the results of the sample of assets studied in this paper do not encourage the view that such a link exists. Our results are, however, encouraging from another point of view. Estimates of economic depreciation are widely used in the imputation of the cost of capital services, $P_{K}$, and in perpetual inventory estimates of capital stocks. As noted above, it is generally assumed that depreciation follows a stationary process, so that the same pattern of depreciation can be applied over time. The findings of this paper support this approach. While depreciation almost certainly varies from year to year in response to a variety of factors, we have found that a major event like the energy crises, which had the potential of significantly increasing the rate of obsolescence, did not in fact result in a systematic change in age-price profiles. This lends confidence to procedures which assume stationarity in order to achieve a 
major degree of simplification (and because non-stationarity is so difficult to deal with empirically). Or, put simply, the use of a single number to characterize the process of economic depreciation (of a given type of capital asset) seems justified in light of the results of this paper. 
Notes

1. These estimates are obtained from the BLS publication, Trends in Multifactor Productivity: _1948-81, and subsequent press releases.

2. Denison (1981a, 1981b) and Nordhaus (1980) provide a detailed survey of the various theories of the productivity slowdown.

3. Tobin's average $q$ is the financial value of a firm divided by the replacement cost of the firm's capital. If that capital becomes obsolete, the value of the firm is reduced and the q ratio declines. This effect is described in greater detail below.

4. Obsolescence, as conventionally defined, refers to the loss in the value of existing capital because it is no longer technologically suited to economic conditions or because technically superior alternatives become available. Obsolescence, in the sense of the Baily hypothesis, refers to a loss in output. As we shall see later in this paper, the two definitions are not equivalent: the second definition implies the first but not vice versa.

5. It should be stressed, here, that the focus of this research is the relationship between energy and economic growth. While the methods used in the paper are almost identical to those developed in earlier studies of economic depreciation (Hulten and Wykoff (1981a, 1981b,), it is not our intention to offer new estimates of economic depreciation or to test the stability of our previous estimates in light of the energy crisis. This latter course would have required: (1) data on a more extensive list of assets than was available for the pre- and postenergy crisis years; (2) estimates of how the energy crisis affected retirements of assets from service; and (3) a precise definition of stability, since the period-to-period change in the depreciation rate of a particular asset may be statistically significant, but the change so small that is of little consequence for the measure of capital (see Bureau of Labor Statistics (1981) for a detailed analysis of this point).

6. In discussions of aggregate growth, $Q$ is interpreted as real value added and the input list is restricted to capital and labor.

7. See Solow (1957) or Jorgenson and Griliches (1967) for the derivation of an equation like (2).

8. For a more complete survey of the literature on the relationship between energy prices and productivity growth, see Berndt and Wood (1985).

9. The assumption, here, is that the rise in energy prices causes a net decline in the utilization of capital stock. Recalling the example of the trucking firm, some capital is used more intensively and other capital less intensively as energy prices change. The direction of the utilization effect is an empirical issue; the theoretical point is that 
utilization effects should not be ignored.

10 This is, if the true growth rate of the total factor productivity residual, $\hat{A}^{*}$, remained at the pre-energy crisis growth rate of measured TFP, $\hat{A}$, the correction $S_{K} \hat{B}$ would equal 1.658 or five times the observed value of this variable.

It is worth noting that Berndt and Wood (1984) show that there is a large potential impact of energy prices on the value of used capital. The relationship between energy prices and used capital prices is studied in detail in subsequent sections of this paper.

11. The VK in (8) is the present value of the expected flow of new income accruing to capital. Equation (11) indicates that this flow can be disaggregated by the vintage of the capital generating that income.

12. In earlier work with age-price profiles, Hulten and Wykoff (1981a, 1981b) corrected for censored sample bias by deflating asset prices by the probability of retirement. We did not make this adjustment in this study because we do not have data on the change in retirement after 1973, and because deflation by the same retirement function would not change the pre- and post-1973 comparison by age-price profiles.

13. The MDNA is a professional organization of dealers in used machine tools. These reports consist of data on auction transactions for a wide range of machine tools submitted by MDNA members. The coverage of these reports obviously varies over time. There were no reports compiled during the years 1971 and 1972 and for some periods the number of observations greatly exceed those reported in other periods.

14. The relationship between serial numbers and the year of manufacture is published for most types and makes of machine tools in The Serial Number Reference Book for Metal Working Machinery, (9th edition) [1983]. In some cases, it was necessary to obtain data for later years directly from the manufacturers.

15. Attempts were made using dummy variables to correct for differences in asset configuration. Except in the few cases noted below, this approach did not yield statistically significant results.

16. Our results also bear on the simulated age-price profiles reported by Berndt and Wood (1984). Our findings suggest that potentially large effects noted by Berndt and Wood did not occur for the assets studied in this paper. It must, however, be noted that Berndt and Wood were concerned with ceteris paribus effects $i, e$. the change in the age-price profile due to a change in energy price, holding other factors constant, while the estimates of this paper refer to mutatis mutandi shifts in the age-price profile.

17. Evidence from other studies does tend to support the conclusions of this paper. In a study of several categories of industrial equipment, Shriver (1986) finds that the rates of the value of seven year old 
equipment to new equipment did not decline appreciably after 1973. For all classes of assets, he reports that the ratio was .33 in $1973, .32$ in 1976, and .34 in 1980. While this study was not specifically intended as an analysis of energy-induced obsolescence, it is noneless noteworthy because of the comprehensiveness of the asset categories studied.

In addition, the study by Wadhwani and Wall (1986) finds no evidence that the energy crisis caused capital to be scrapped prematurely in the U.K. Again, while this does not bear directly on the obsolescence of the U.S. capital stock, it does indicate that another prediction of the obsolescence hypothesis is not verified.

18. In a putty-clay vintage mode1, the adoption of a new energy efficient technology immediately after an energy price shock may be unprofitable if an even more energy efficient technology is on the horizon. In this case, the newly adopted technology might be rendered obsolete itself and a firm would have an incentive to defer investment and prolong its use of existing equipment. Alternatively, uncertainty about the permanence of the energy price shock might also lead to an optimal strategy of utilizing old equipment more intensively than originally planned.

19. A further complication arises because the energy price shocks may have affected the market for used assets on the demand side. For example, to the extent that construction equipment were used to increase coal production, the energy crisis may have increased utilization of construction equipment rather than a reduction. If there is any mismeasurement of capital, it would work in the opposite direction of the Baily hypothesis. 


\section{References}

Ackerlof, George (1970), "The Market for Lemons" Quarterly Journal of Economics, No. 3, August, 488-500.

Baily, Martin N. (1981), "Productivity and the Services of Capital and Labor," Brookings Papers on Economic Activity, 1, 1-50.

Berndt, Ernst R. (1980), "Energy Price Increases and the Productivity Slowdown in U.S. Manufacturing," The Decline in Productivity Growth, Federal Reserve Bank of Boston, Conference Series No. 22, Boston, 60-89.

Berndt, Ernst R. and David 0. Wood (1979), "Engineering and Econometric Interpretations of Energy Capital Complementary," American Economic Review, vo1. 69, June, 342-54.

and (1984), "Energy Price Changes and the Induced Revaluation of Durable Capital in U.S. Manufacturing during the OPEC Decade," M.I.T. Energy Lab Report No. 84-003.

and (1985), "Energy Price Shocks and Productivity Growth,"

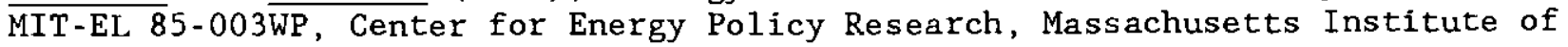
Technology.

Berndt, Ernst R., Shunseke Mori, Takamitsu Sawa, and David 0. Wood (1985), "Energy Price Shocks and Productivity Growth in Japan and U.S.

Manufacturing Industry," paper presented at the Conference on Productivity Growth in Japan and the United States, Conference on Research in Income and Wealth, Cambridge, Mass., August 26-28.

Denison, Edward F. (1979a), "Explanations of Declining Productivity Growth," Survey of Current Business, vol. 59, August, 1-24.

(1979b), Accounting for Slower Economic Growth: The United States in the $1970^{\prime}$ s, Brookings Institution, Washington, D.C.

Hudson, Edward A. and Dale W. Jorgenson (1978), "Energy Prices and the U.S. Economy, 1972-1976," Natural Resources Journal, 18, October, 877-97.

Hulten, Charles R, and Frank C. Wykoff (1981a), "The Estimation of Economic Depreciation Using Vintage Asset Prices," Journal of Econometrics, 15, Apri1, 367-96.

and (1981b), "The Measurement of Economic Depreciation," in Charles $\mathrm{R}$. Hulten, ed., Depreciation. Inflation. and the Taxation of Income from Capital, The Urban Institute Press, Washington, D.C.

Jorgenson, Dale W. (1984), "The Role of Energy in Productivity Growth," in John W. Kendrick, ed, International Comparisons of Productivity and the Causes of the Slowdown, Ballinger, Cambridge, Mass., 279-323.

Jorgenson, Dale W. and Barbara M. Fraumeni, "Relative Prices and Technical 
Change," in Ernest R. Berndt and Barry Field, eds., Modeling and Measuring Natural Resource Substitution, M.I.T. Press, Cambridge, Mass, $17-47$.

Jorgenson, Dale W. and Zvi Griliches (1967), "The Explanation of Productivity Change," Review of Economic Studies, 34, August, 249-83.

Nordhaus, William D. (1980), "Policy Responses to the Productivity Slowdown," The Decline in Productivity Growth, Federal Reserve Bank of Boston, Conference Series No. 22, Boston, 147-72.

Rasche, Robert H. and John A. Tatom (1977a), "The Effects of the New Energy Price Regime on Economic Capacity, Production, and Prices," Federa1 Reserve Bank of St.Louis Review, vo1. 59, May, 2-12.

and (1977b), "Energy Resources and Potentia1 GNP," Federal Reserve Bank of St.Louis Review, vo1. 59, June, 10-24.

Solow, Robert M. (1957), "Technical Change and the Aggregate Production Function," Review of Economics and Statistics, 39, August, 312-20.

(1970), Growth Theory: An Exposition, Oxford University

Press, New York and Oxford.

Shriver, Keith A. (1986), "A Statistical Test of the Stability Assumption Inherent in Empirical Estimates of Economic Depreciation," Journal of Economic and Socia1 Measurement, 14, 145-153.

Wadhwani, Sushil and Martin Wa11 (1986), "The U.K. Capital Stock - New Estimates of Premature Scrapping," Oxford Review of Economic Policy, vol. 2, No. 3, 44-45.

Summers, Lawrence H. (1981), "Taxation and Corporate Investment: A qTheory Approach," Brookings Papers on Economic Activity, 1, 67-127.

U.S. Department of Labor, Bureau of Labor Statistics (1983), Trends in Multifactor Productivity, 1948-81, Bulletin 2178, U.S.G.P.O., Washington, D.C., September 1983. 


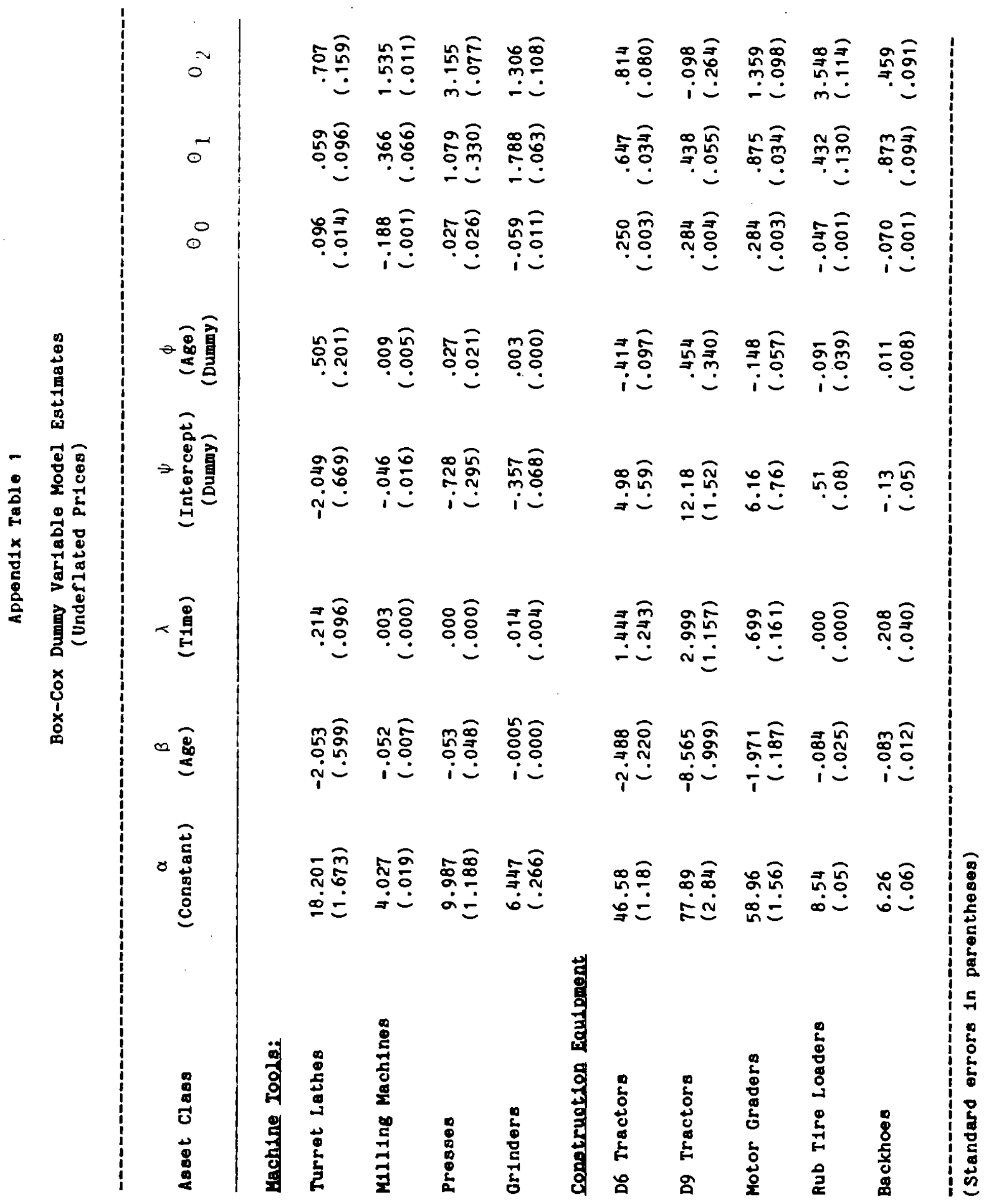



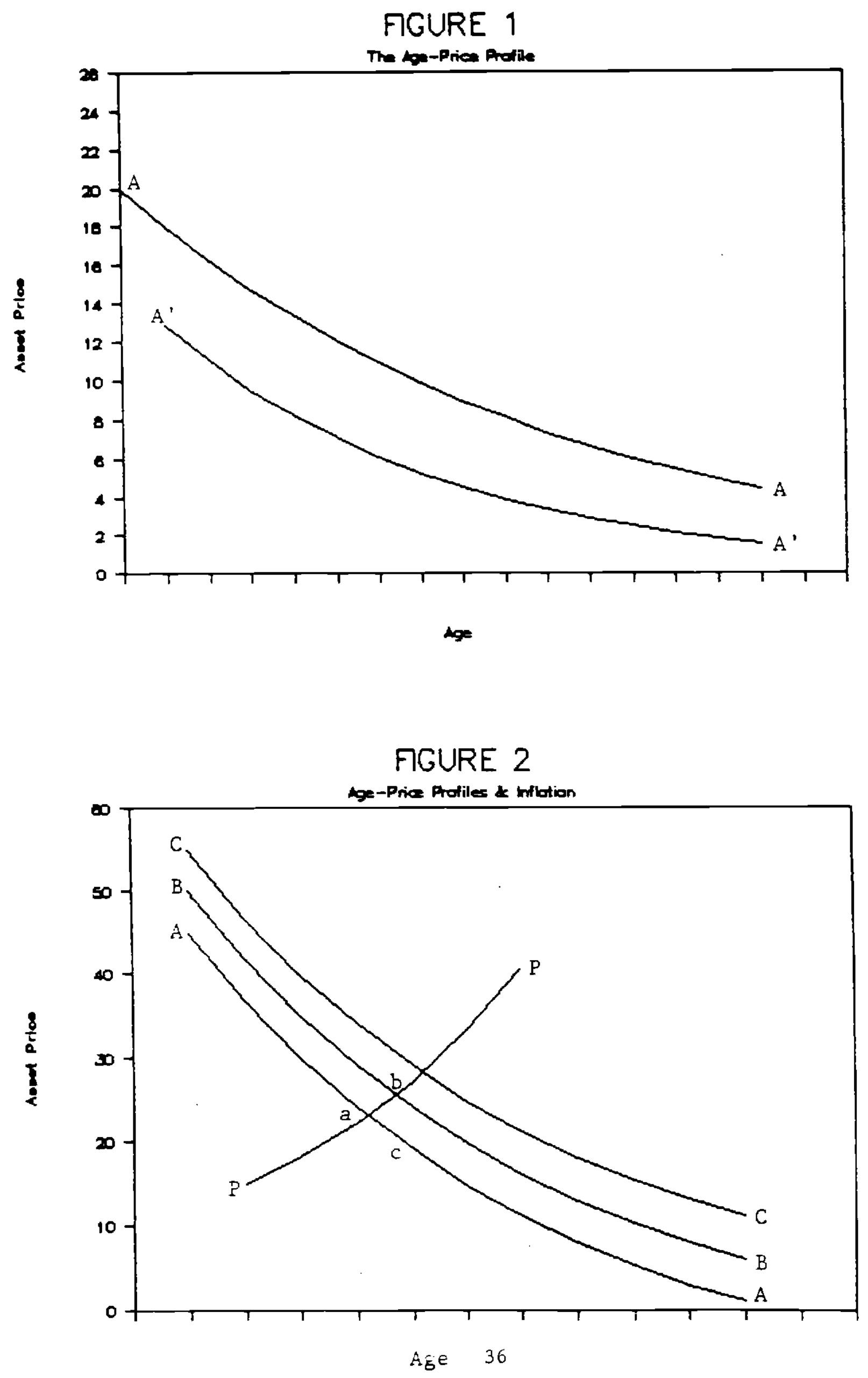


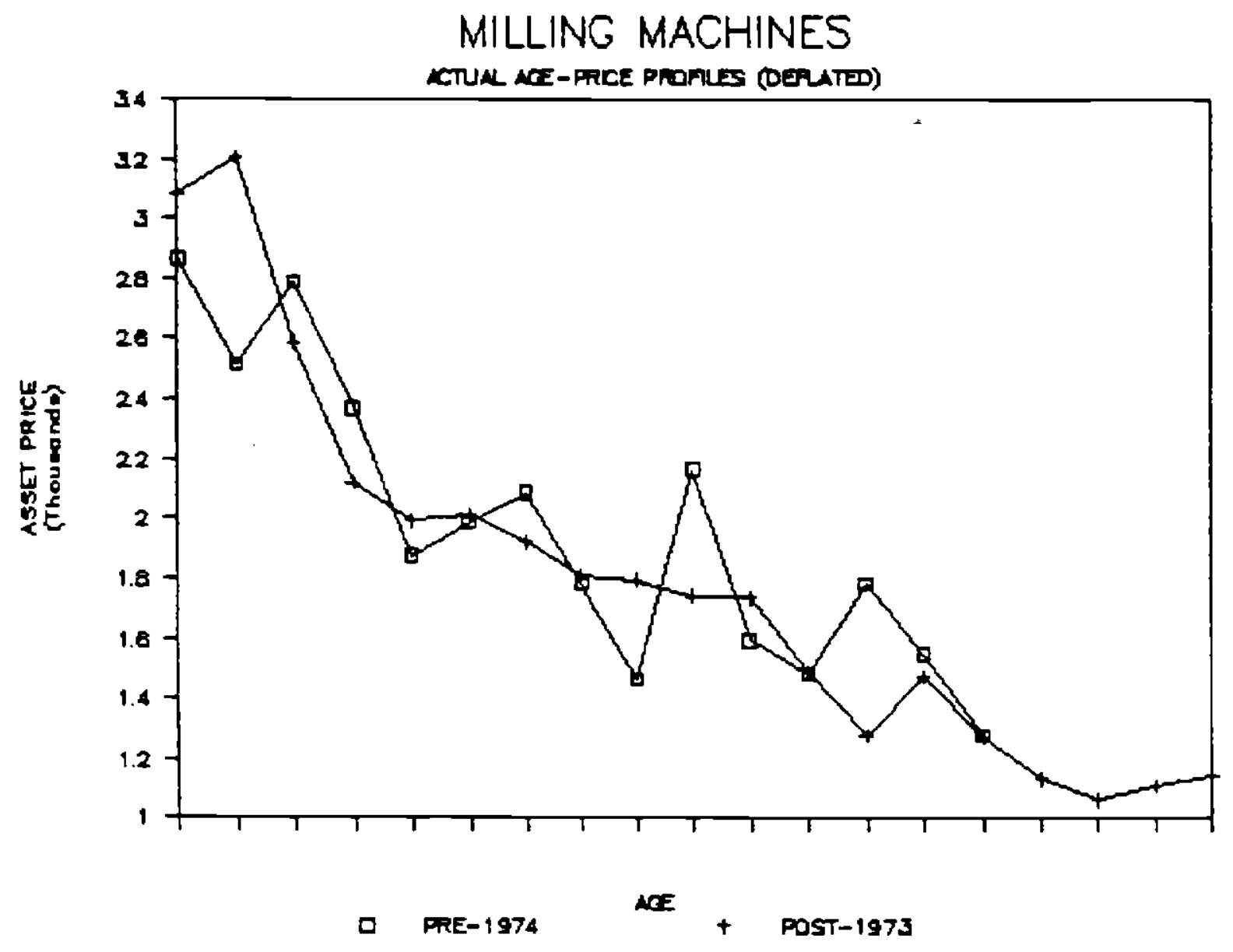

TURRET LATHES

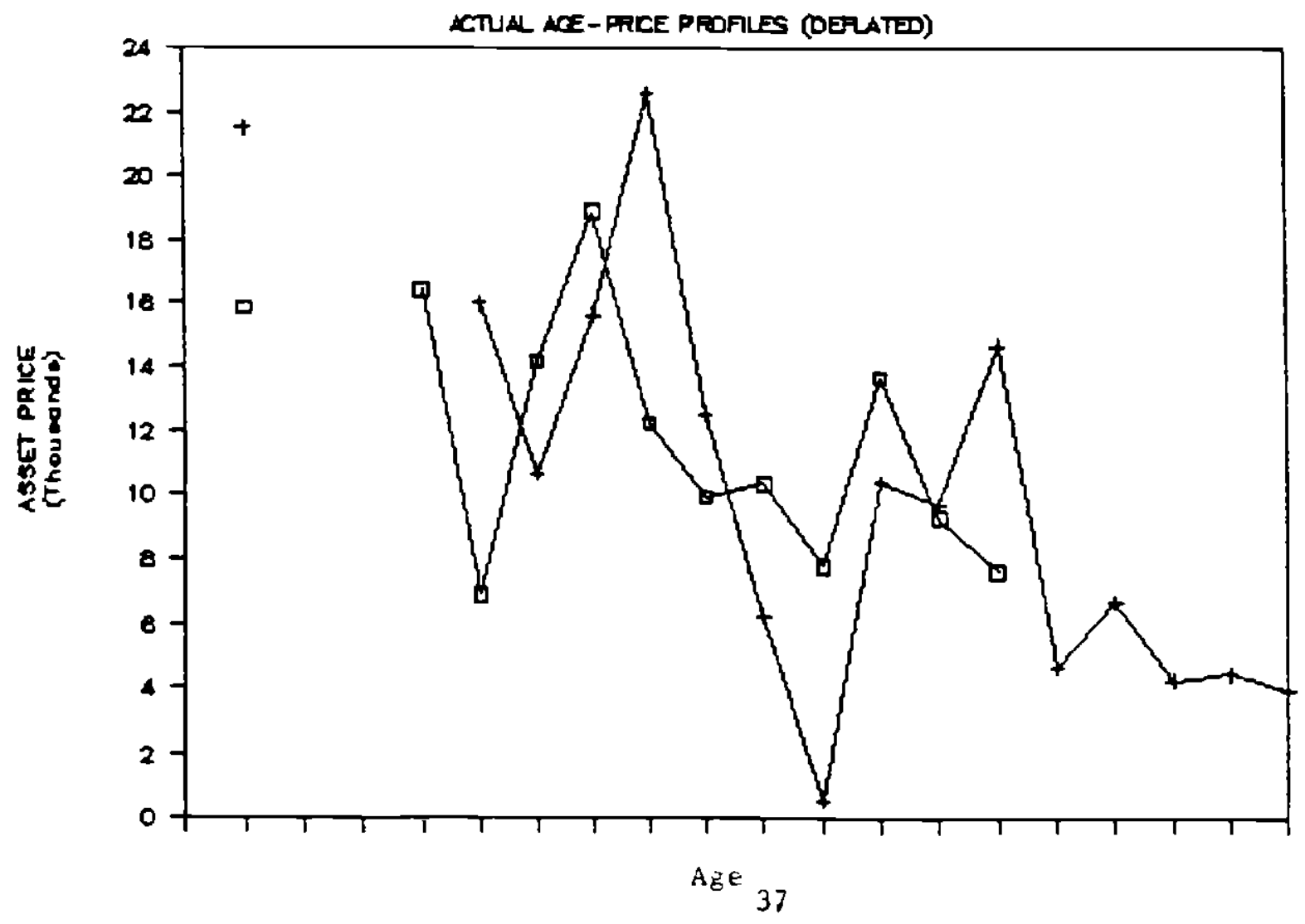



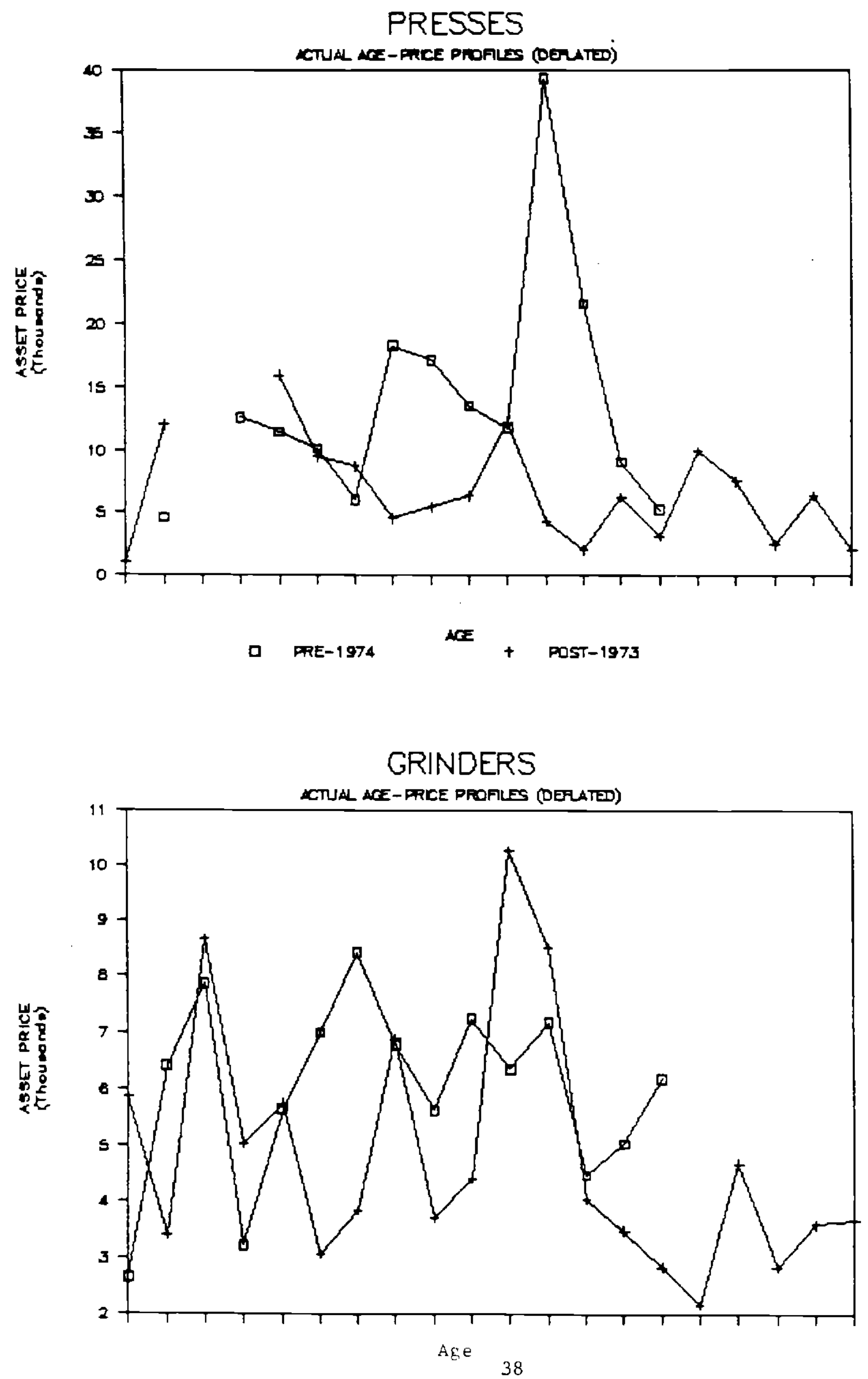
FIGURE 3 (continued)

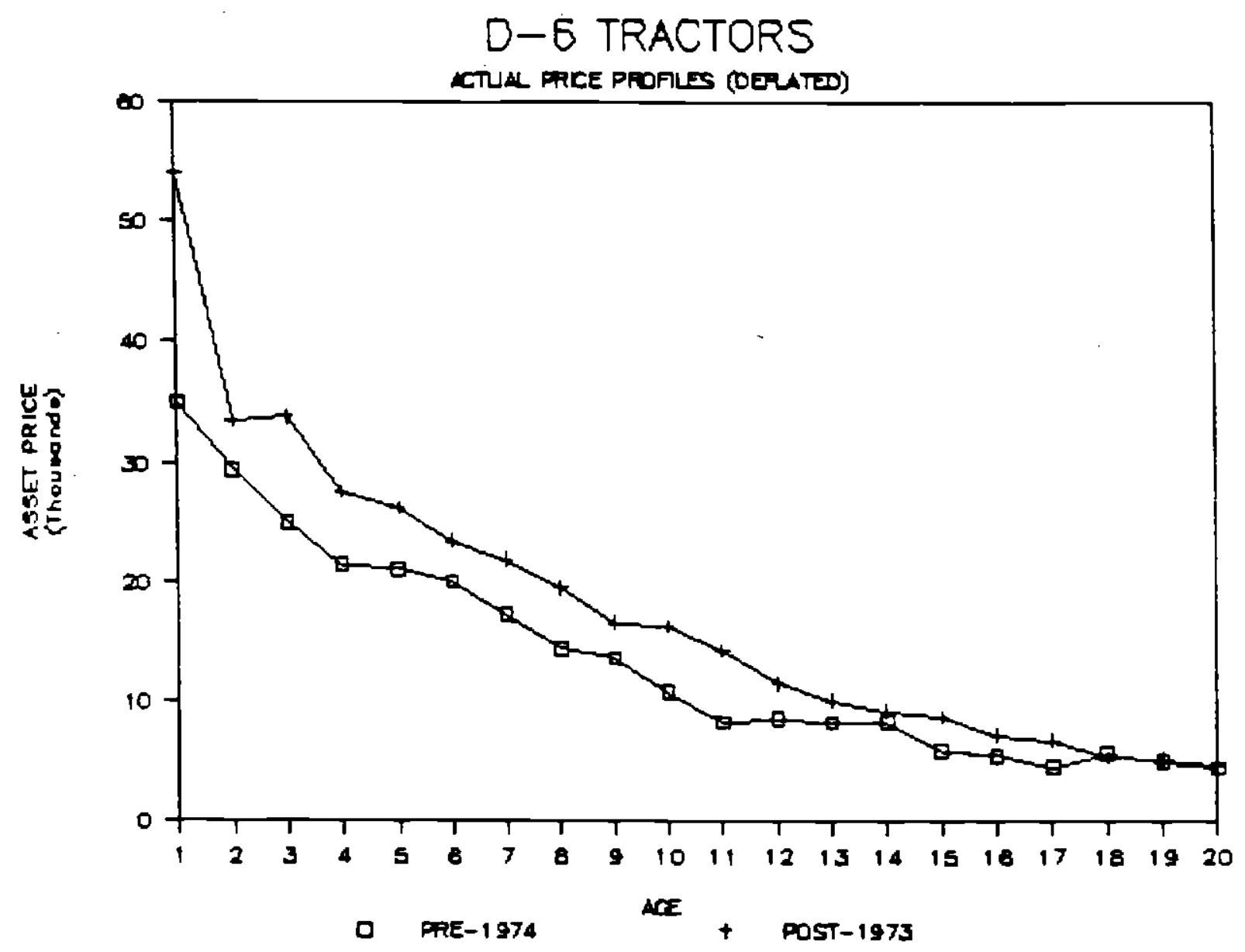

D9 TRACTORS

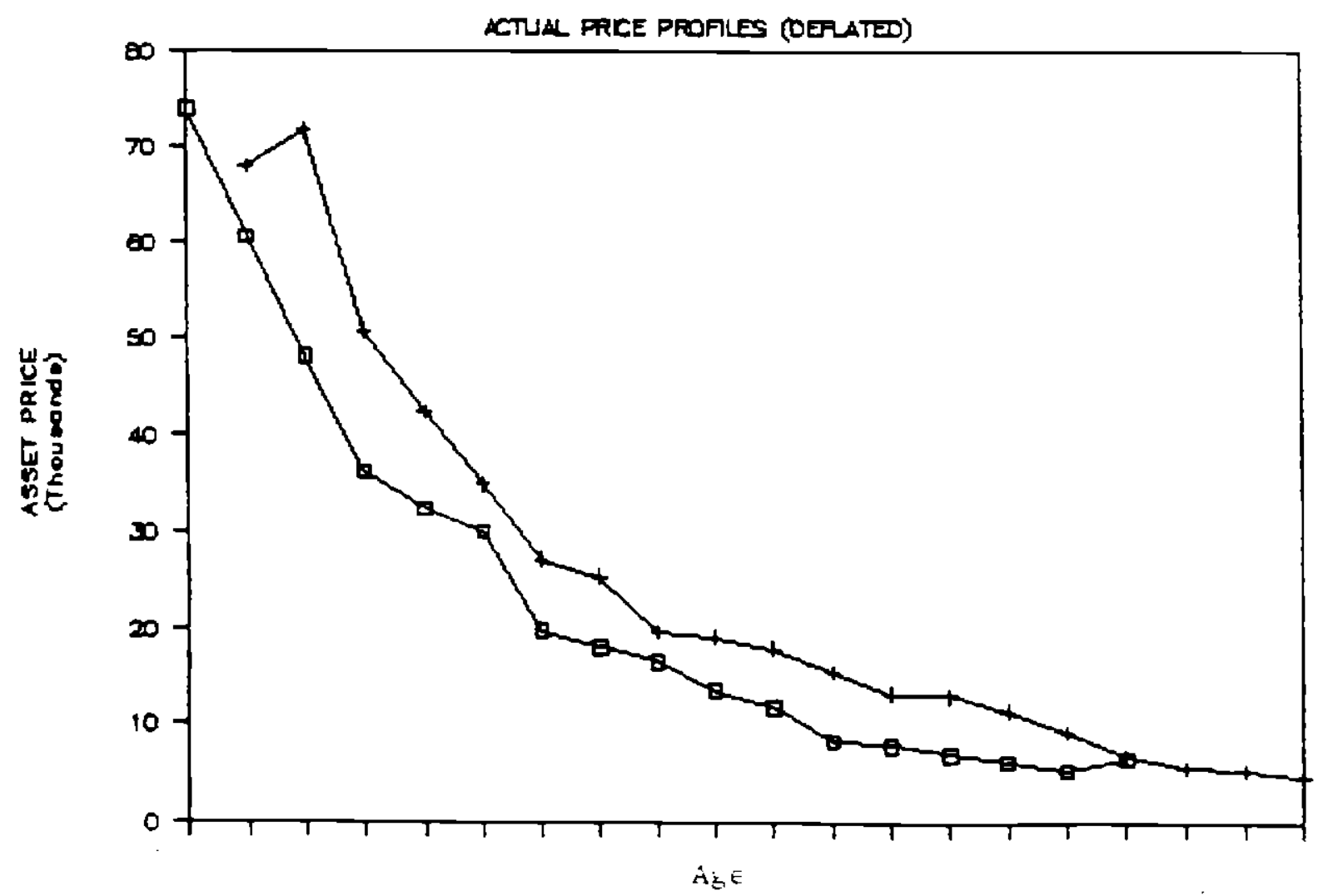



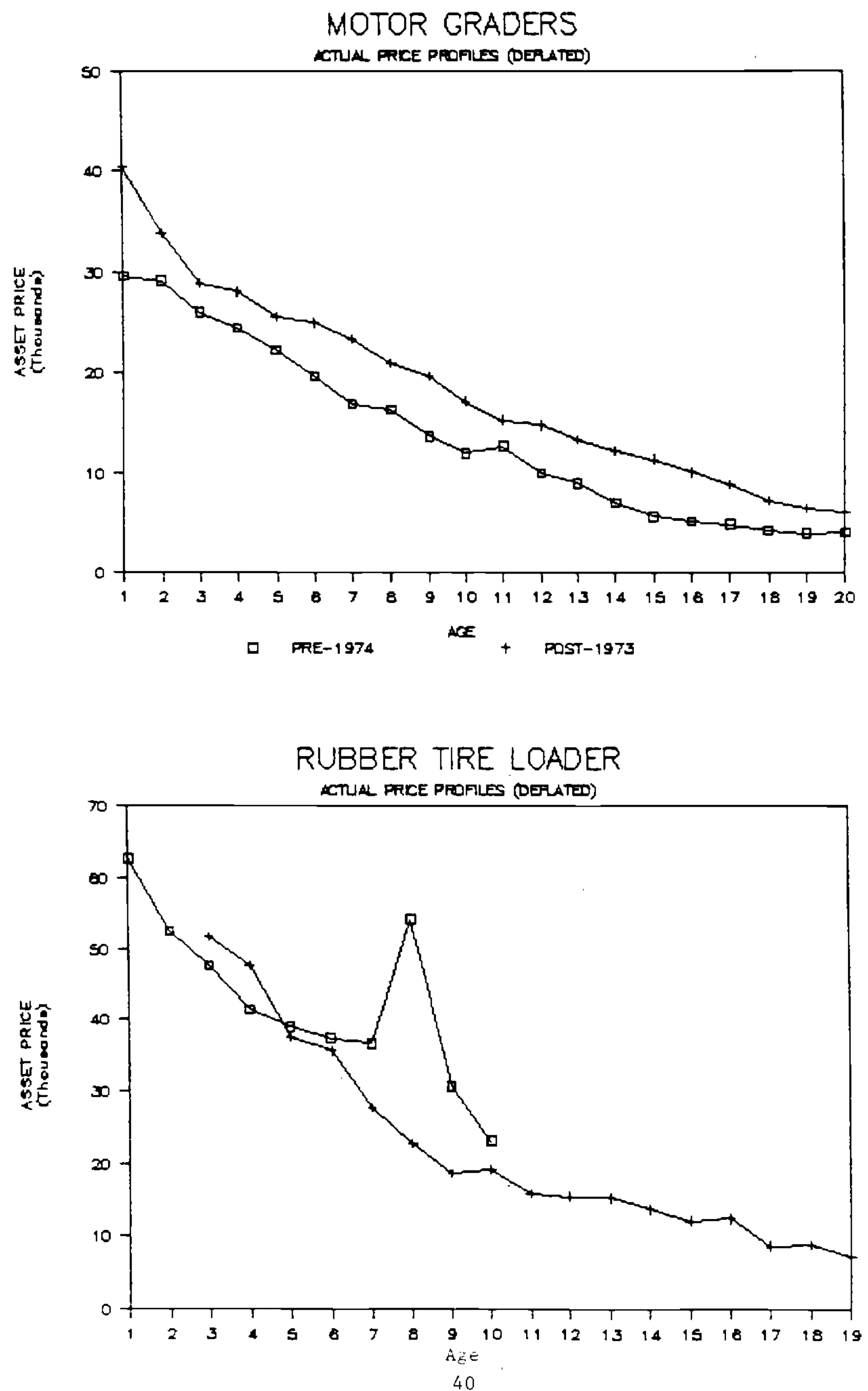


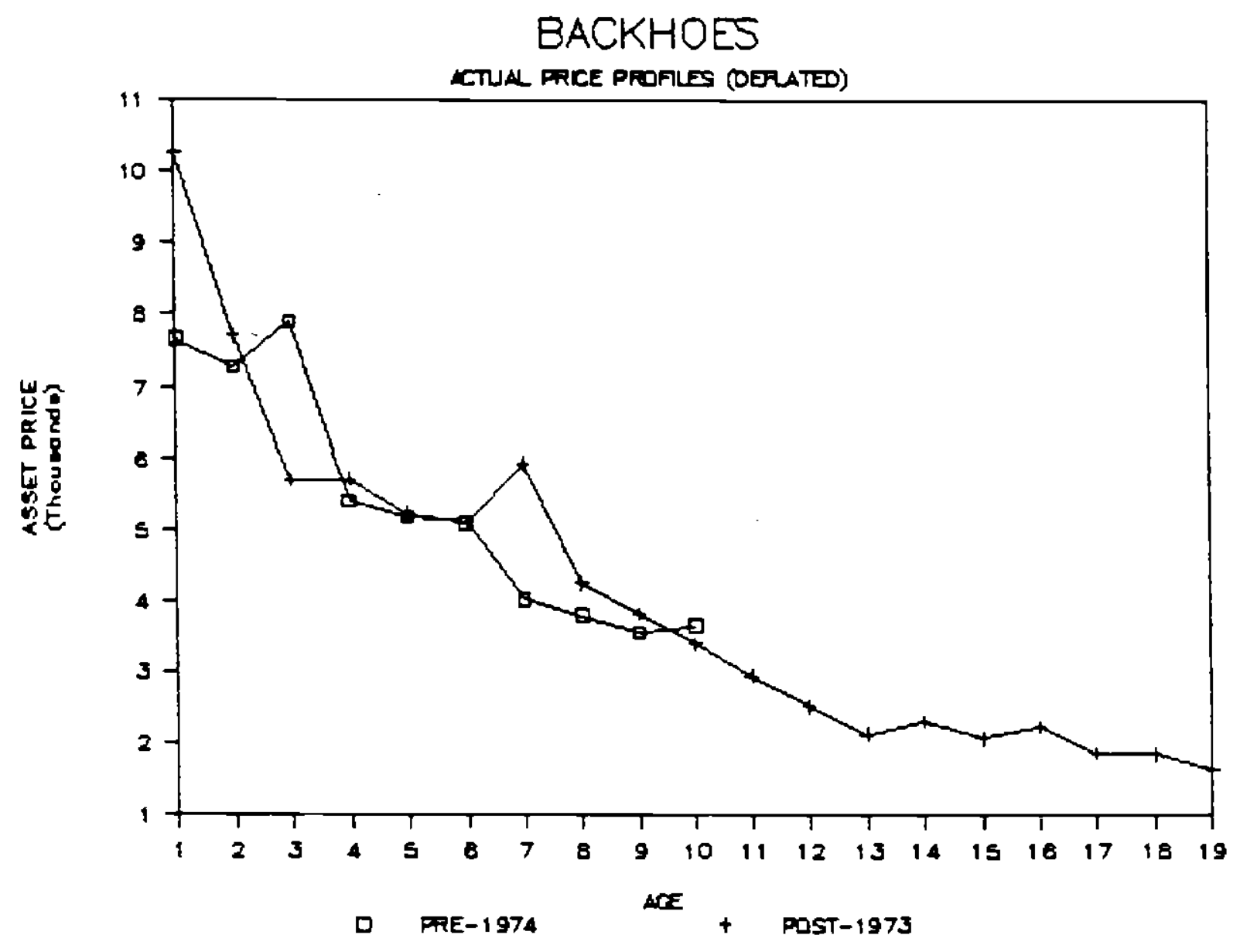



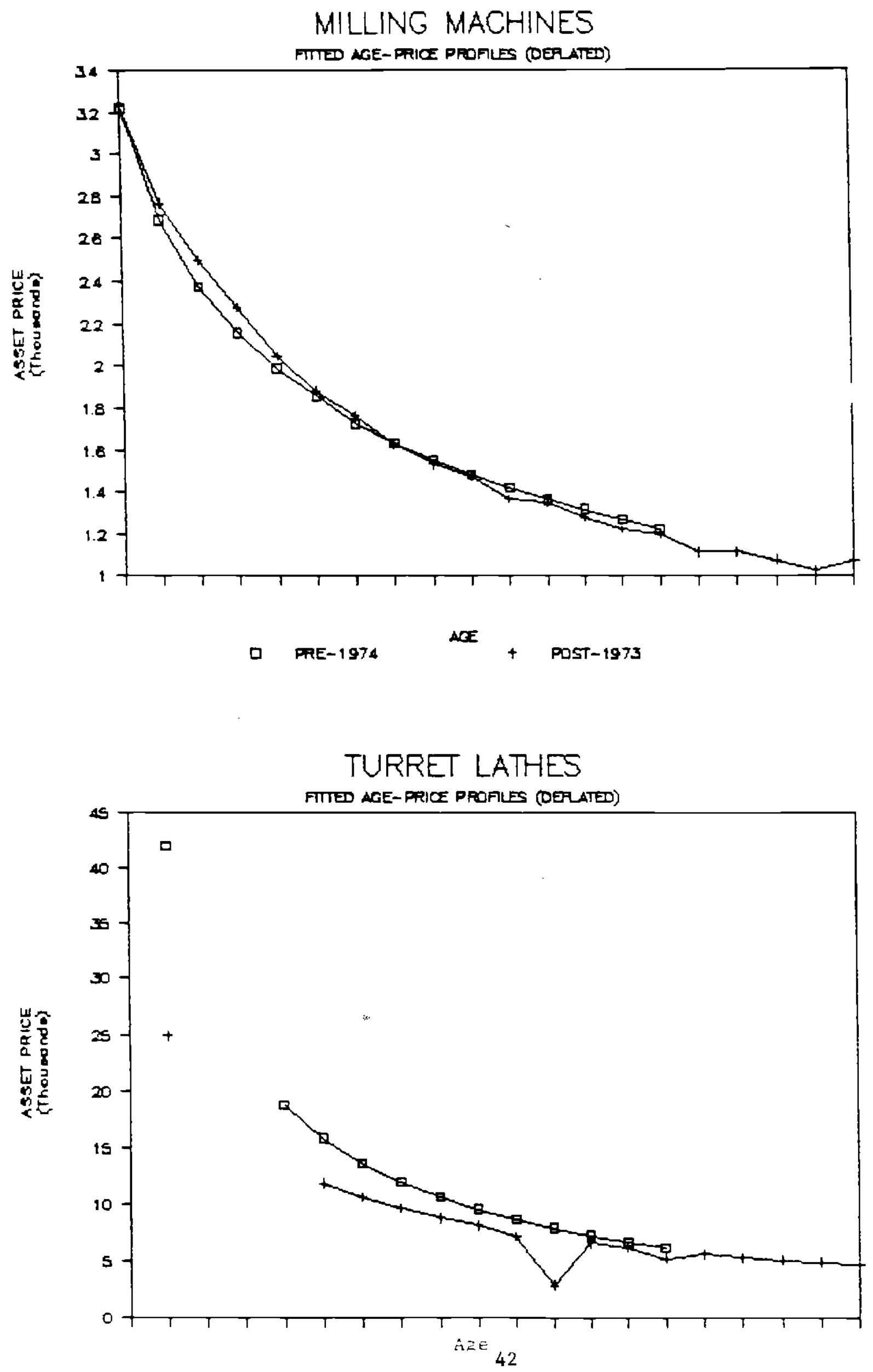


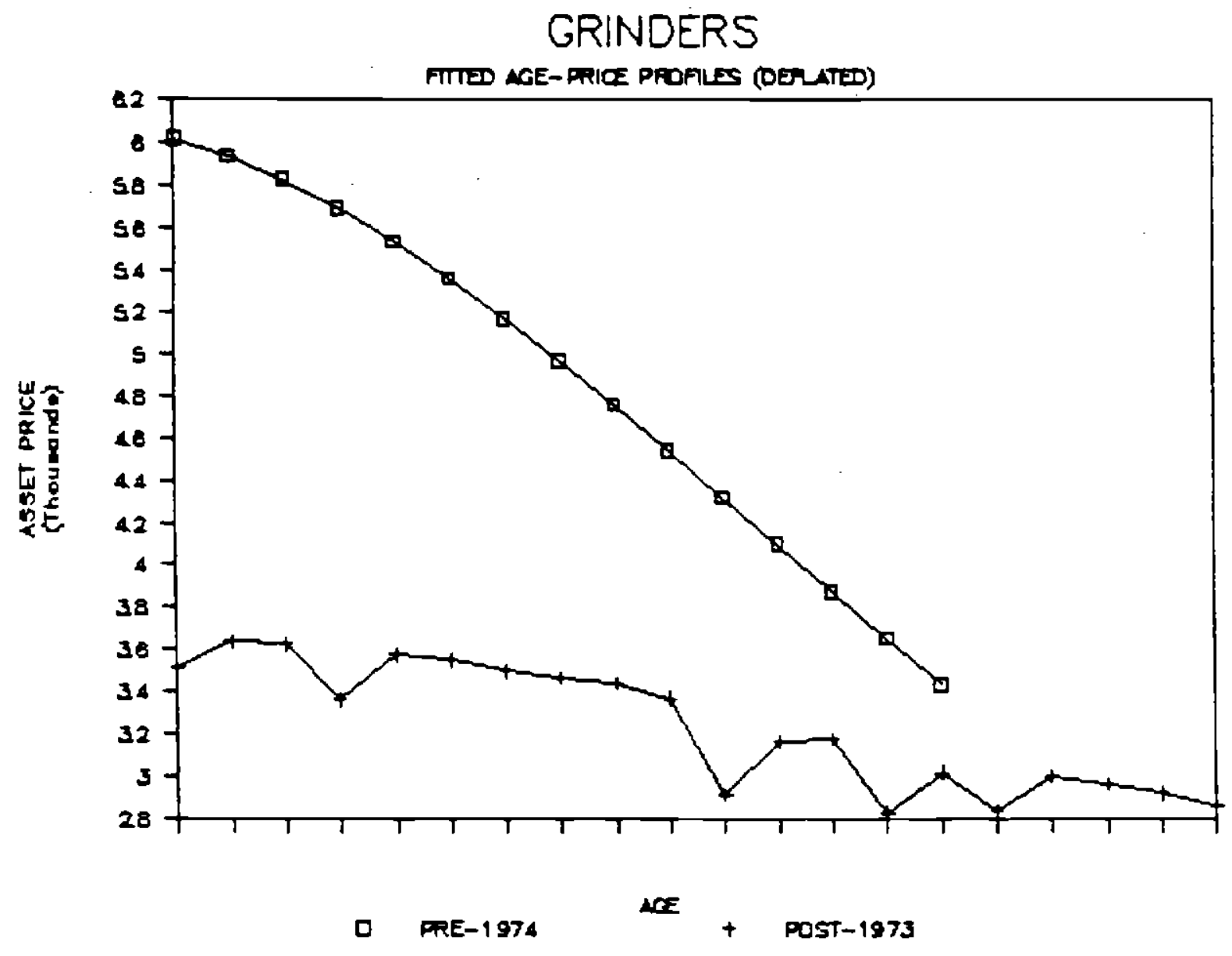

PRESSES

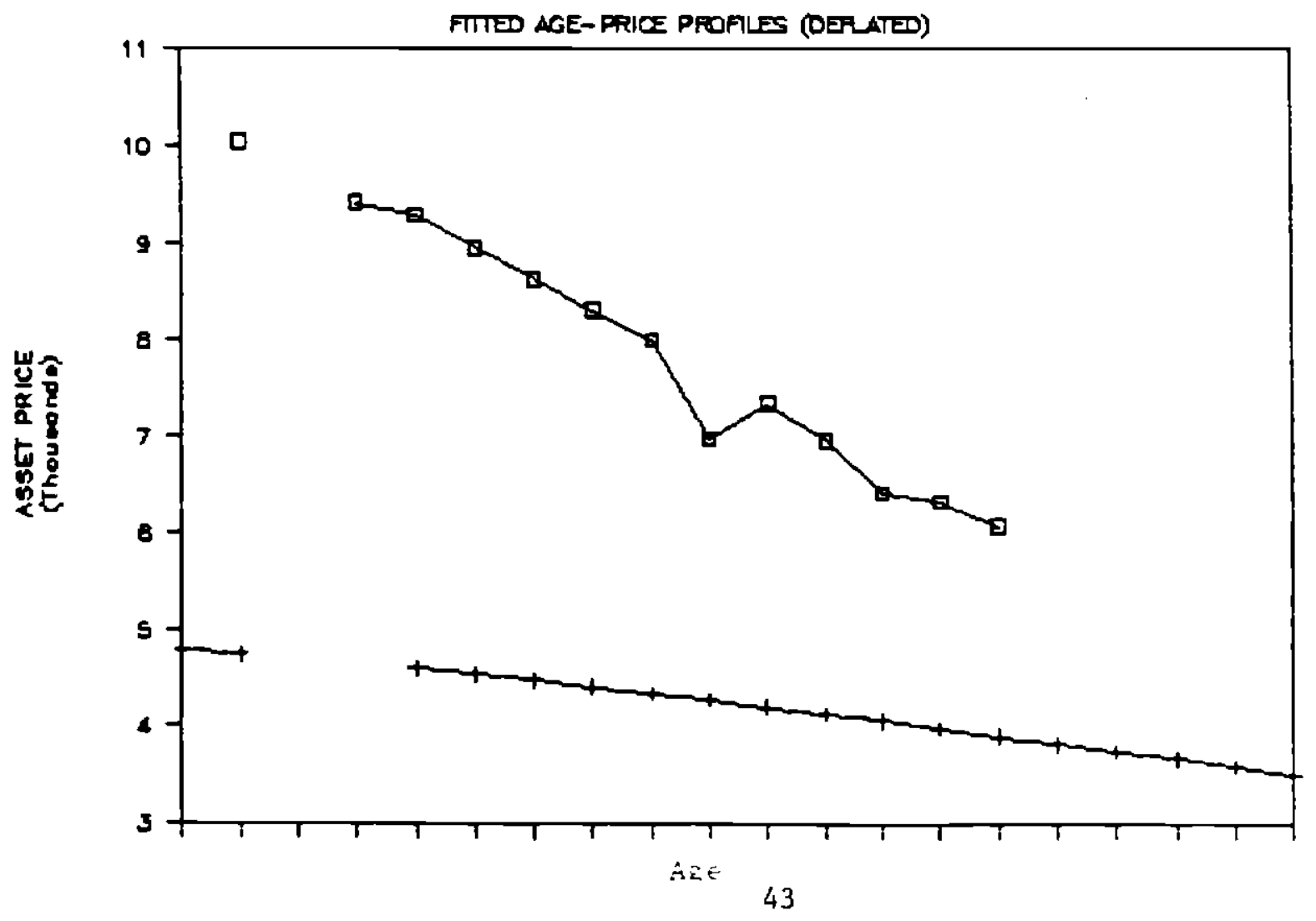



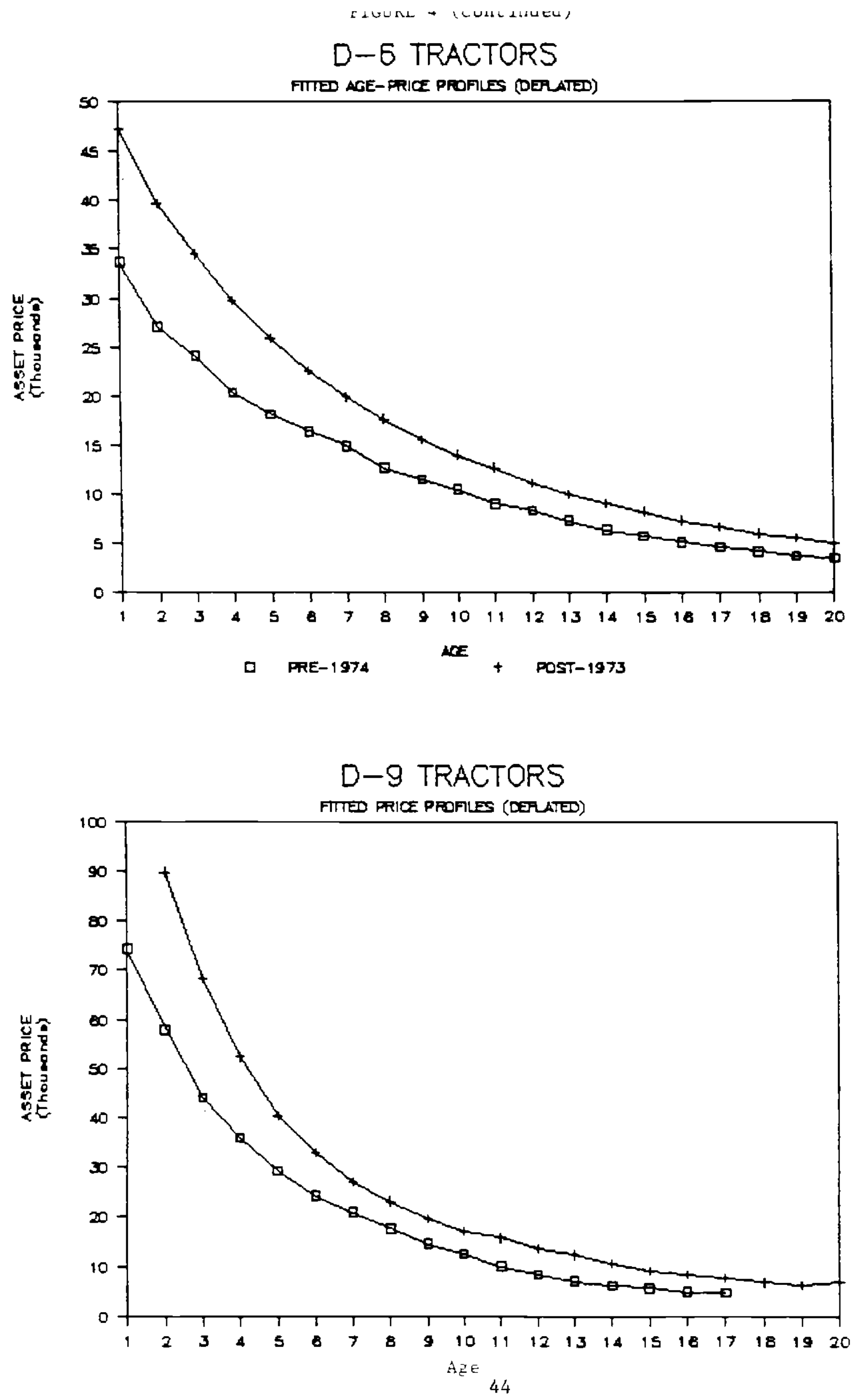


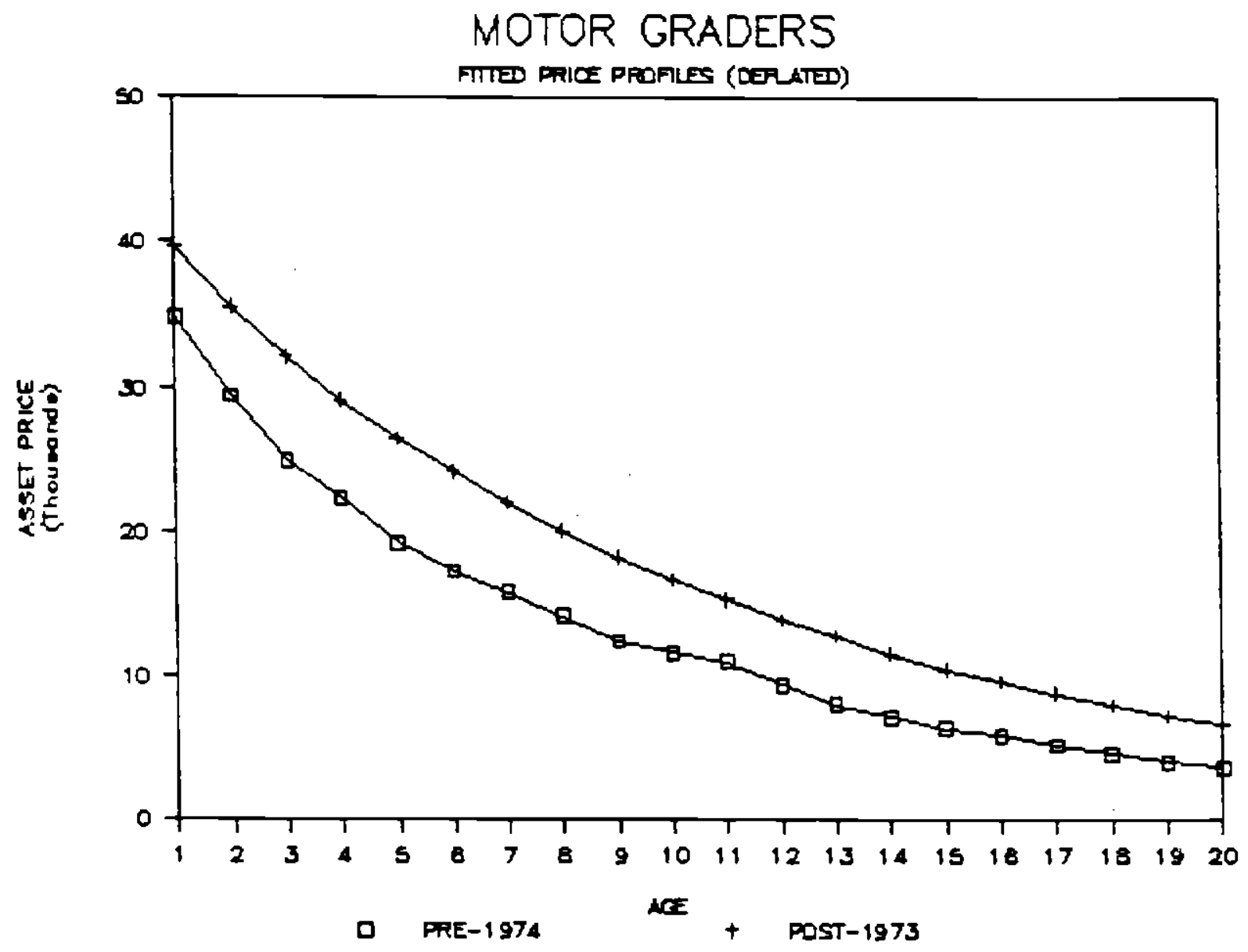

RUBBER TIRE LOADER

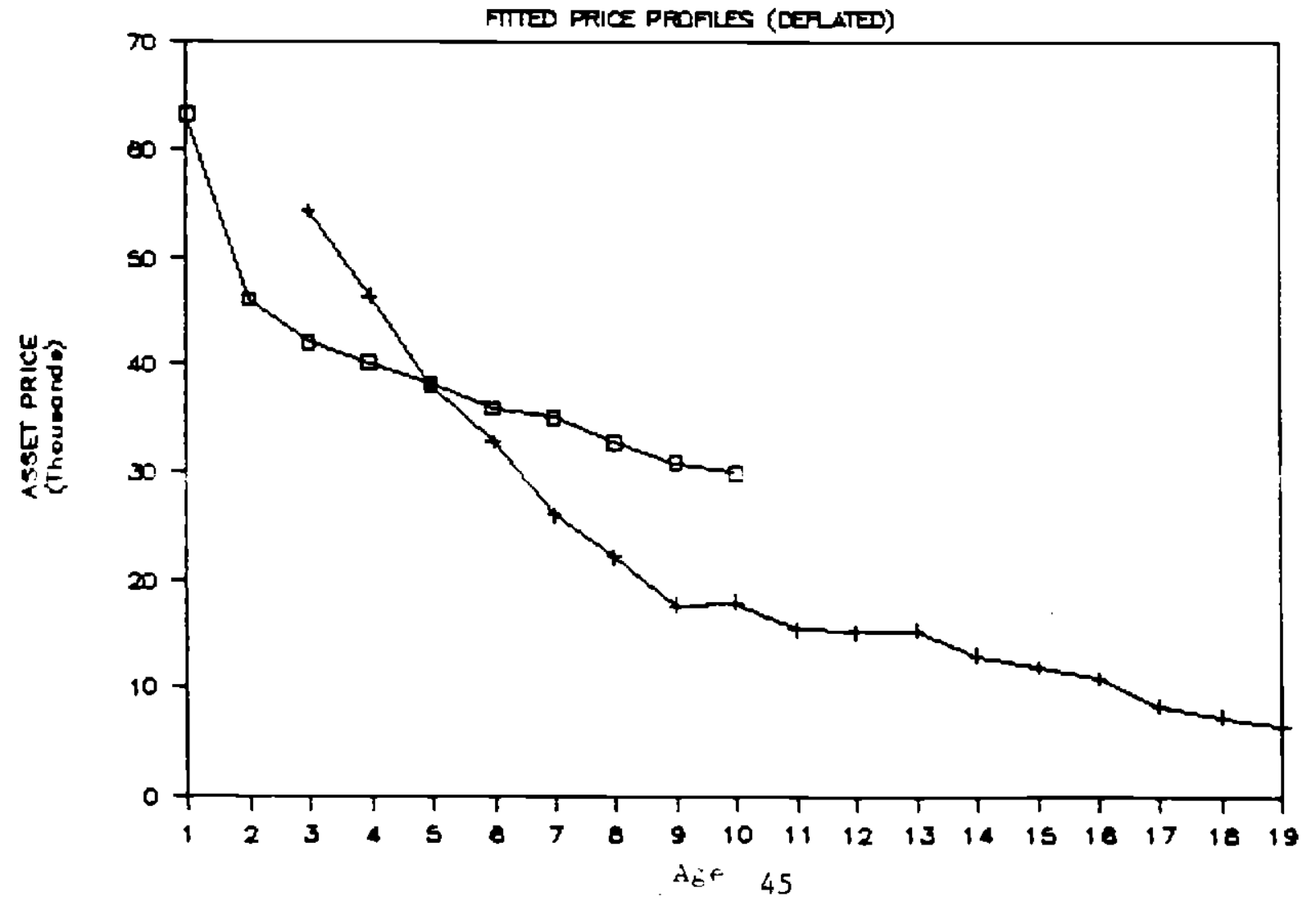




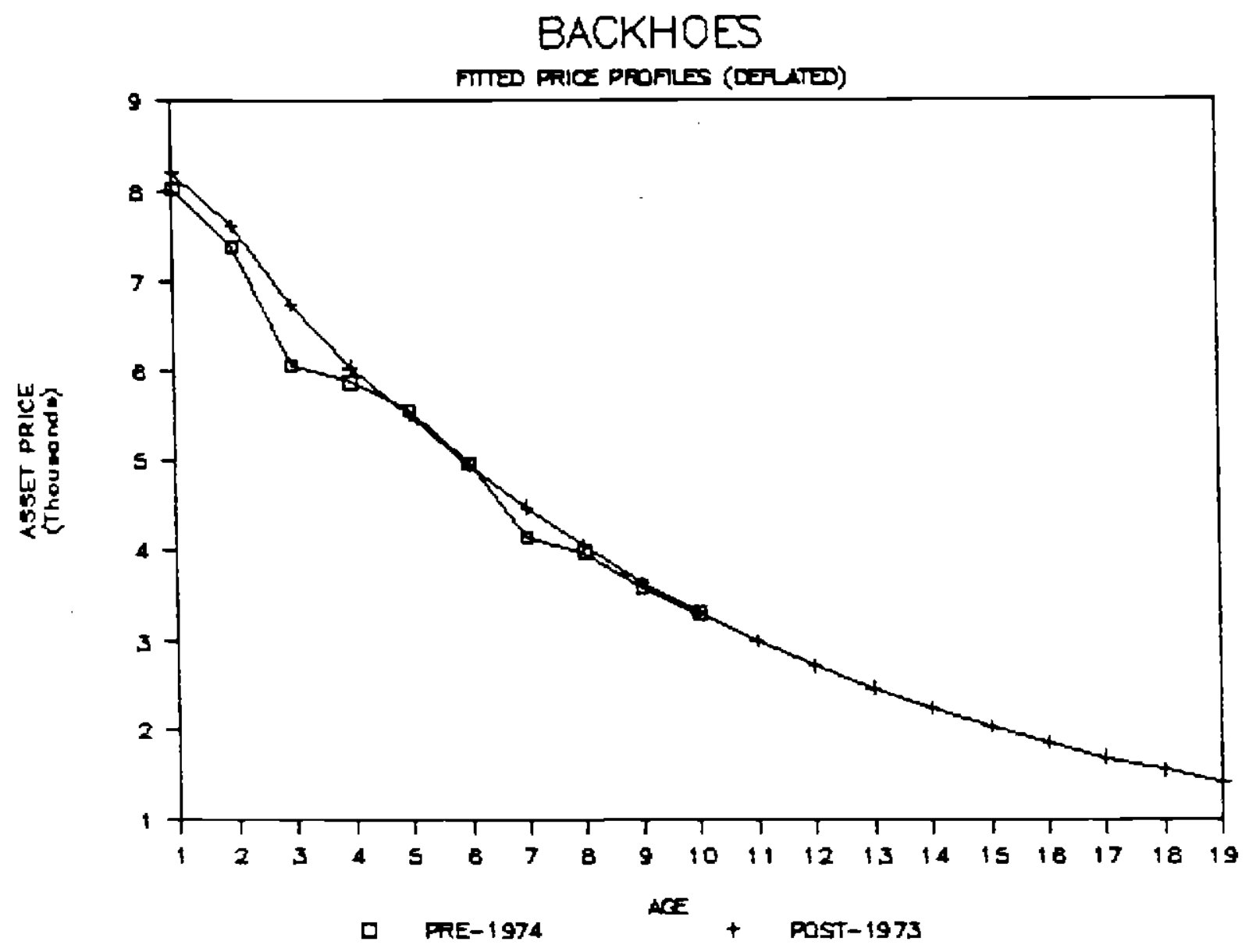

